\title{
REVIEW
}

\section{Promising Applications of Additive-Manufactured (3D-printed) Electrochemical Sensors for Forensic Chemistry}

\author{
Sílvia V. F. Castroํ, Raquel G. Rocha ${ }^{1}$, Afonso F. João ${ }^{1,2}$, Eduardo M. Richter ${ }^{1}$, Rodrigo A. A. \\ Munoz ${ }^{1 *}$ 迥 \\ ${ }^{1}$ Núcleo de Pesquisa em Eletroanalítica (NuPE), Instituto de Química, Universidade Federal de Uberlândia, \\ 38400-902, Uberlândia, MG, Brazil \\ ${ }^{2}$ Department of Math and Natural Science, Púnguè University, Chimoio, Mozambique
}

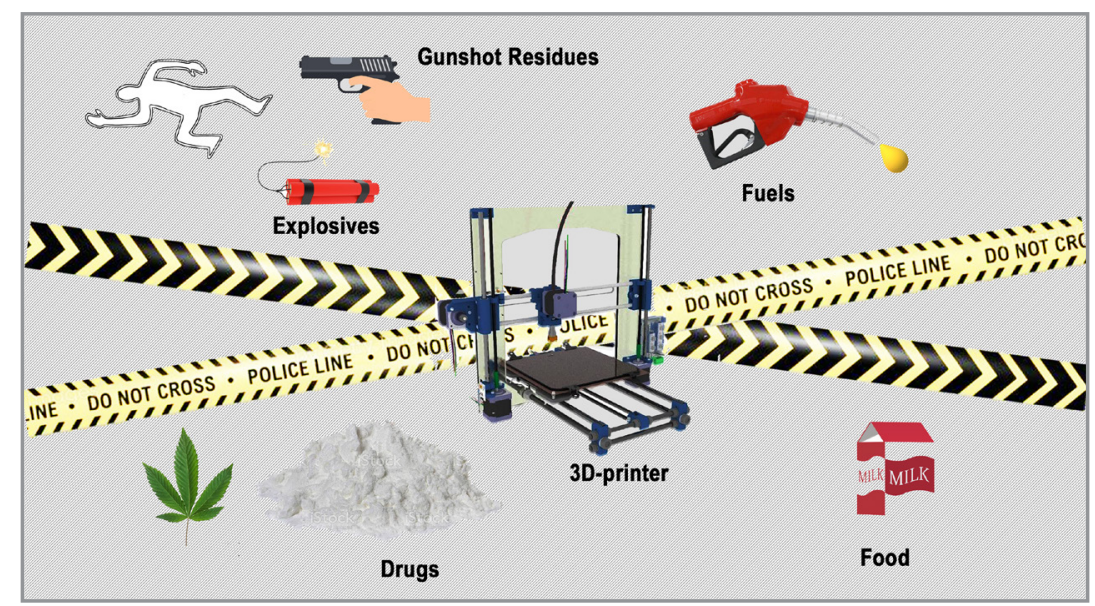

Additive-manufacturing is one of the major pillars of the new industrial revolution and the three-dimensional (3D) printing technology has been highlighted in this scenario. Among the many areas benefited by 3D-printing, the development of electrochemical sensors has appeared in evidence in the last years. One potential application of 3D-printed electrochemical sensors is devoted to forensic chemistry, which demands for portable analytical methods that can provide on-site measurements and thus bring a relevant information in loco. In this context, this review highlights the recent contribution of 3D-printing technology on the development of electrochemical sensors with great promises for on-site analysis in "real-world" forensic scenarios. From the detection of trace explosives, gunshot residues, illicit drugs and chemical threats, to the measurement of adulterants in food and fuels, we show the wide range of applications that 3D-printed electrochemical sensors have been proposed and future demands that can be addressed by such a powerful, affordable, and accessible tool.

Keywords: Forensics, Illicit drugs, Crime Scene, Electrodes, Composite.

Abbreviations: 3D, three dimensional; AAS, atomic absorption spectroscopy; ABS, acrylonitrile butadiene styrene; ASTM, American Society for Testing and Materials; BIA, batch injection analysis; CB/PLA, carbon black/polylactic acid; DMF, dimethylformamide; DNT, 2,4-dinitrotoluene; DPV, differential pulse voltammetry; EIS, electrochemical impedance spectroscopy; FDM, fused deposition modeling; G/PLA,

Cite: Castro, S. V. F.; Rocha, R. G.; João, A. F.; Richter, E. M.; Munoz, R. A. A. Promising Applications of Additive-Manufactured (3D-printed) Electrochemical Sensors for Forensic Chemistry: A Review. Braz. J. Anal. Chem., 2022, 9 (34), pp 79-105. doi: http://dx.doi.org/10.30744/brjac.2179-3425.RV-50-2021 
graphene/polylactic acid; GSR, gunshot residue; HMTD, hexamethylene triperoxide diamine; HPLC, High performance liquid chromatography; ICP OES, inductively coupled plasma with optical emission spectrometry; ICP-MS, inductively coupled plasma with mass spectrometry; IMS, ion mobility spectrometry; LIBS, laser-induced breakdown spectroscopy; NAA, neutron activation analysis; NPS, novel psychoactive substances; PB, Prussian blue; PETN, pentaerythritol tetranitrate; PGE, pencil graphite electrode; RDX, cyclo-1,3,5-trimethylene-2,4,6-trinitramine; SEM/EDX, scanning electron microscopy with energy dispersive X-ray analysis; SLA, stereolithography; SLM, selective laser melting; SPE, screen-printed electrode; SWASV, square-wave anodic stripping voltammetry; SWV, square-wave voltammetry; TATP, triacetone triperoxide; TNT, 2,4,6-trinitrotoluene;

\section{INTRODUCTION}

Three-dimensional (3D) printing, which is considered an additive manufacturing technology, has been considered one of the pillars of the fourth industrial revolution due to the enormous benefits brought to several areas, including dentistry, medicine, electronics, aerospace, engineering, civil construction, food and many others [1]. The chemistry area has also been greatly impacted by 3D printers, as they can provide fast and low-cost fabrication of geometrically complex 3D structures and many parts or objects to replace broken pieces of instruments inside research and teaching laboratories [2]. Moreover, 3D printing can be used to fabricate versatile reaction ware for chemical synthesis [3] as well as electrodes for rechargeable batteries [4]. Probably, electrochemistry and analytical chemistry are two major traditional areas that have been taken several advantages from this technology for several applications as reported in recent revisions for electrochemical energy application [5], electrochemical sensors [6], analytical detectors [7] and microfluidic devices [8].

One field of investigation that can be greatly benefited by 3D printing is the forensic science, specifically forensic chemistry. A recent review highlighted the applications of 3D printing in forensic science, including crime scene reconstruction, ballistic reconstruction, pattern and impression evidence, forensic archeology, medicine, anthropology, taphonomy, odontology and engineering; however, there are no mentions of forensic chemistry [9]. Aiming to inspire forensic chemistry researchers, this review shows potential applications of 3D printing for electrochemical sensing of different molecules of forensic interest. The focus on electrochemistry is explained by the inherent advantages provided by electrochemical methods for portable analysis, which is an Achilles tendon in forensic chemistry, for instance most analytical methods for onsite monitoring of chemical evidences are based on colorimetric assays. Hence, this review aims to shed light on electrochemical sensors for forensic analyses as well as on the introduction of 3D printing in the development of affordable and large-scale electrochemical devices aiming at obtaining chemical evidences to aid police forces or regulatory agencies to solve criminal issues. The review is divided into three sections (a: explosive and gunshot residue; b: illicit drugs; and c: food and fuel) in which 3D-printed electrodes were successfully applied. Special attention is given to the fused deposition modelling (FDM) which has been demonstrated a powerful tool for the fabrication of low-cost electrochemical devices. As conclusions, many other possibilities of 3D printing for forensic electrochemistry are envisaged showing great perspectives of such a powerful tool.

\section{EXPLOSIVES AND GUNSHOT RESIDUE}

The development of new analytical methods for the detection of explosives is one of the fields of forensic analysis that has attracted great interest by different research groups [10,11]. This interest is a consequence of the need for finding alternatives to improve public security, since explosives are commonly used in terrorist attacks [12]. In this context, the application of chemical knowledge combined with portable instrumentation has made possible the development of analytical devices that enable the detection of traces of explosives at the crime scene to provide information to assist in the identification of suspects. Some of the widely used explosive compounds are 2,4,6-trinitrotoluene (TNT), 2,4-dinitrotoluene (DNT), cyclo-1,3,5-trimethylene-2,4,6-trinitramine (RDX), pentaerythritol tetranitrate (PETN), triacetone triperoxide (TATP), and hexamethylene triperoxide diamine (HMTD) [10,13]. 
The literature presents some methods commonly used in the identification and determination of these explosives, with great emphasis on ion mobility spectrometry (IMS), Raman and colorimetric detection methods, which have been widely used over the past few years [11]. Additionally, electrochemical methods have also been widely explored due to some special features, such as sensitivity, low cost, easy miniaturization, and portable instrumentation, which can be combined with chemically-modified electrodes to generate electrochemical sensors with improved selectivity and stability [10,14]. Among the main conductive materials used for the development of electrochemical sensors, we highlight the large number of studies involving carbon-based electrodes [15-19].

With the increase of interest in 3D printing, a variety of electrochemical devices have emerged, and the analysis of explosives has also become the object of study by several research groups, as showed in Table I. Tan et al. demonstrated the utilization of a gold plated-3D printed stainless steel electrode for the determination of TNT and DNT, as summarized in Table I - Line A [20]. The 3D-printed metallic sensor was built using the SLM printing technique, and subjected to a gold electroplating step. Differential pulse voltammetry (DPV) was the selected electrochemical technique for the analysis of explosives. To evaluate the performance of the proposed sensor, the authors performed comparative studies with a glassy carbon electrode (GCE). Importantly, on bare 3D-printed electrode, no electrochemical signs of DNT and TNT were observed, which highlights the need for modifications of the electrode surface to improve the electrochemical performance of such electrodes. This improvement was attributed to the increase in surface area and electrocatalytic properties of the sensor. The gold-plated 3D-printed metallic sensor showed better sensitivity, 3.6 times greater than GCE in the determination of DNT, while for TNT, the sensitivity was 1.4 times greater than GCE. The results also evidenced a good linear range for DNT using the 3D-printed electrode (60 to $\left.220 \mu \mathrm{mol} \mathrm{L}^{-1}\right)$ in comparison with GCE (1 to $\left.200 \mu \mathrm{mol} \mathrm{L}^{-1}\right)$. For TNT, the obtained linear range was set between 220 and $400 \mu \mathrm{mol} \mathrm{L} \mathrm{L}^{-1}$.

In addition to explosives, the authors also demonstrated the application of the sensor for the determination of fenitrothion, a pesticide that may be found in contaminated natural waters [20]. Considering that metallic electrodes can be used for several applications in electroanalysis, including forensic electrochemistry, the selective laser melting (SLM) technique would provide great promises for electrochemical sensing; however, an SLM 3D-printer presents a very high cost compared with other 3D printers, such as FDM, and thus is less accessible to many laboratories. 
Table I. 3D printed electrochemical sensors applied for the determination of explosives and gunshot residue

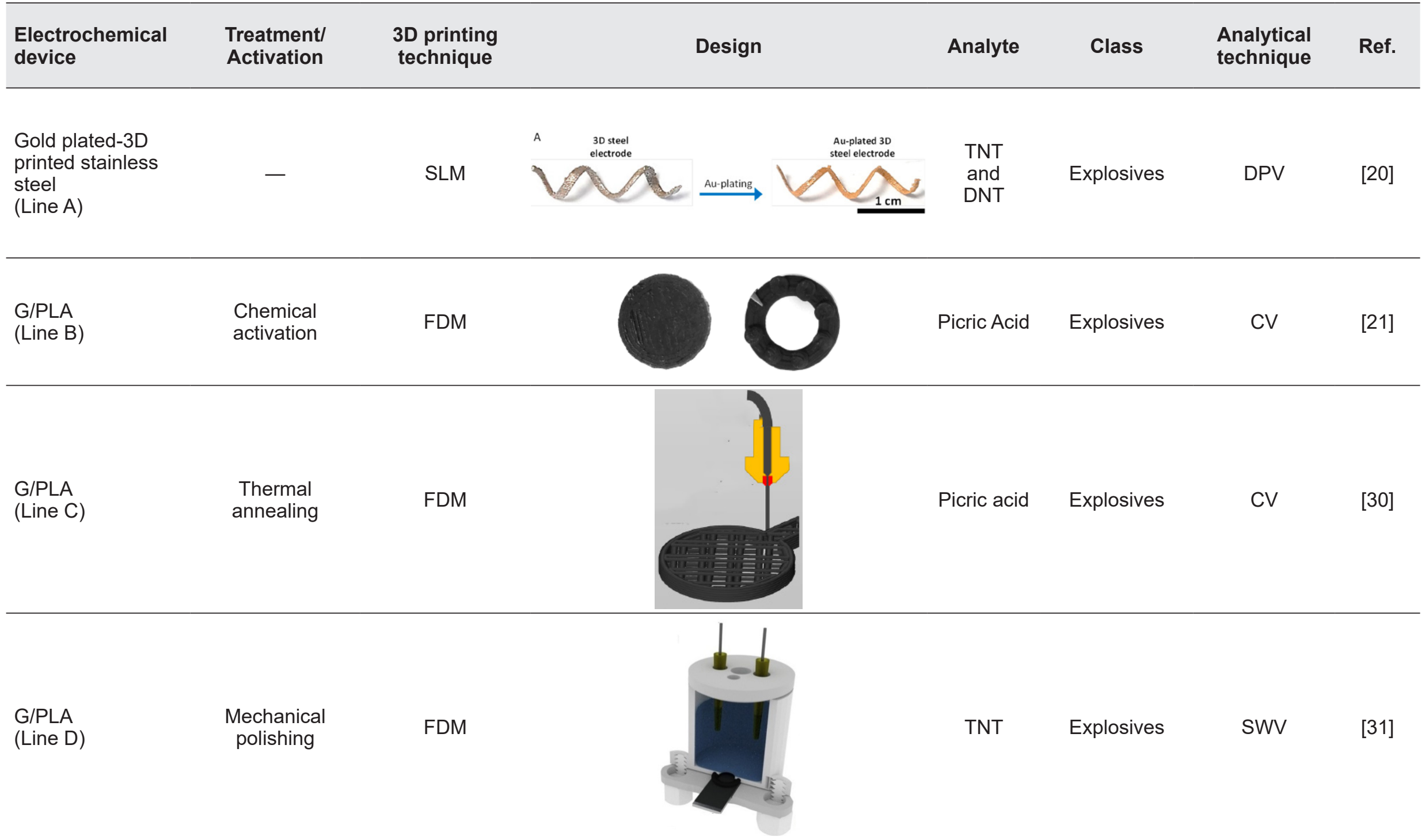


Table I. 3D printed electrochemical sensors applied for the determination of explosives and gunshot residue (Continuation)

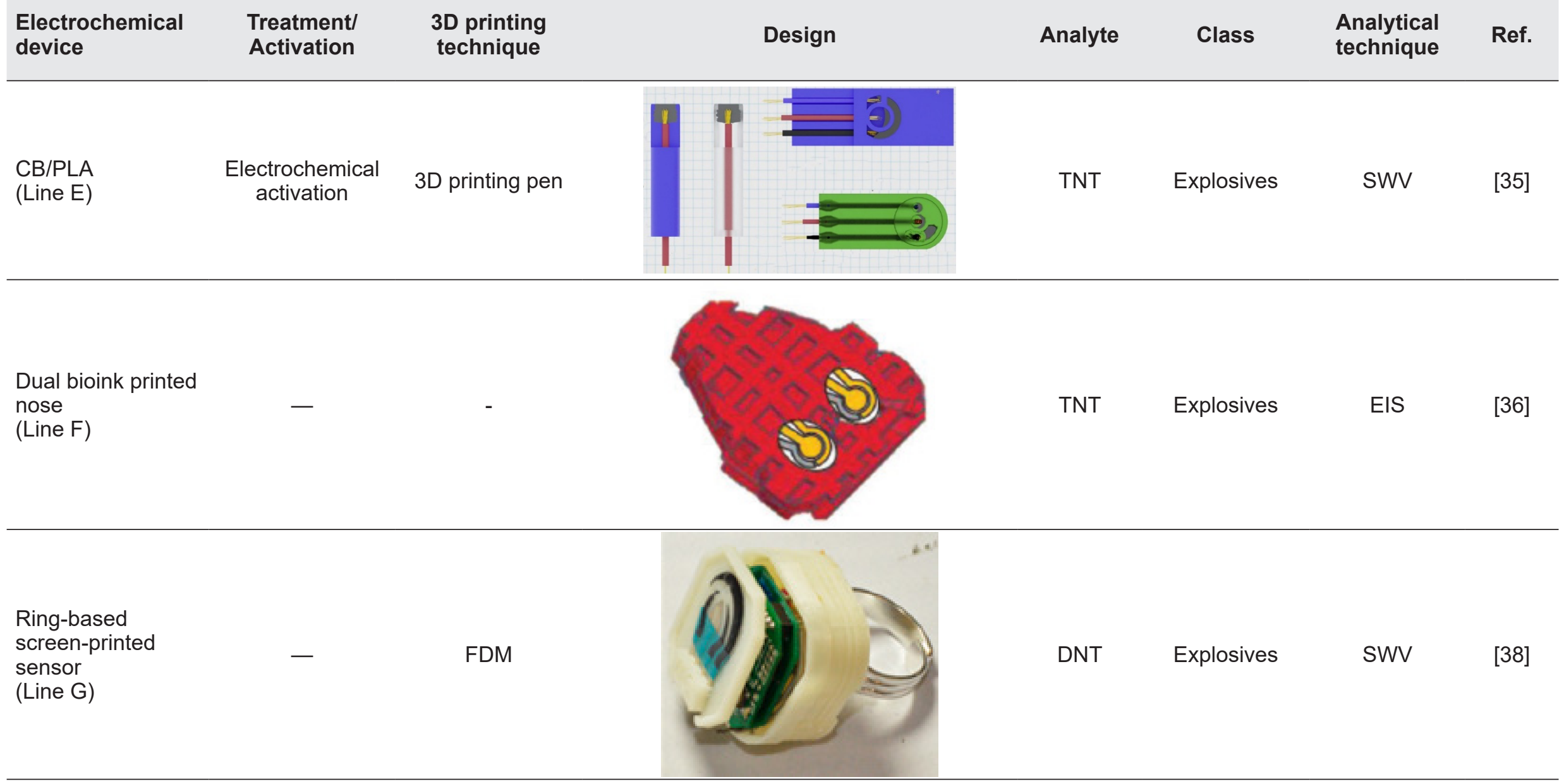


Table I. 3D printed electrochemical sensors applied for the determination of explosives and gunshot residue (Continuation)

\begin{tabular}{|c|c|c|c|c|c|c|c|}
\hline $\begin{array}{l}\text { Electrochemical } \\
\text { device }\end{array}$ & $\begin{array}{l}\text { Treatment/ } \\
\text { Activation }\end{array}$ & $\begin{array}{l}\text { 3D printing } \\
\text { technique }\end{array}$ & Design & Analyte & Class & $\begin{array}{l}\text { Analytical } \\
\text { technique }\end{array}$ & Ref. \\
\hline $\begin{array}{l}\text { G/PLA } \\
\text { (Line H) }\end{array}$ & $\begin{array}{l}\text { Mechanical } \\
\text { polishing } \\
\text { and chemical } \\
\text { activation }\end{array}$ & FDM & & $\begin{array}{l}\mathrm{Pb}^{2+} \text { and } \\
\mathrm{Sb}^{3+}\end{array}$ & $\begin{array}{l}\text { Gunshot } \\
\text { residue }\end{array}$ & SWASV & [62] \\
\hline
\end{tabular}

Electrochemical device: G/PLA: graphene/polylactic acid; CB/PLA: carbon black/polylactic acid.

3D printing technique: SLM: selective laser melting; FDM: fused deposition modelling.

Analytical technique: DPV: differential pulse voltammetry; CV: cyclic voltammetry; SWV: square-wave voltammetry; EIS: electrochemical impedance spectroscopy.

Images reprinted with permission from American Chemical Society:

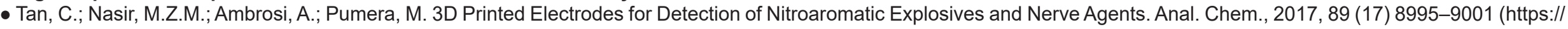

doi.org/10.1021/acs.analchem.7b01614). Copyright (C) 2017 American Chemical Society. [20]

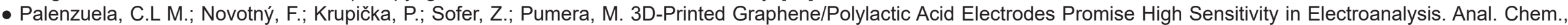

2018, 90, 5753-5757 (https://doi.org/10.1021/acs.analchem.8b00083). Copyright @ 2018 American Chemical Society. [21]

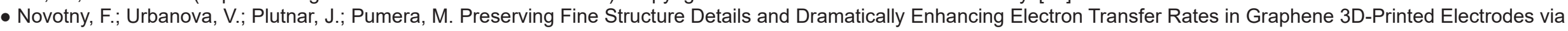

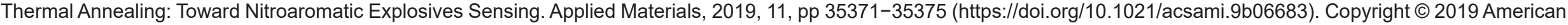
Chemical Society. [30]

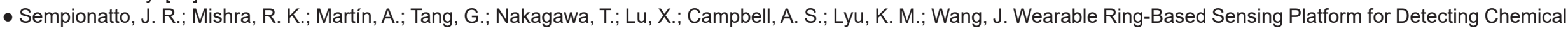
Threats. ACS Sensors, 2017, 2 (10), pp 1531-1538 (https://doi.org/10.1021/acssensors.7b00603). Copyright @ 2017 American Chemical Society. [38]

Images reprinted with permission from Elsevier:

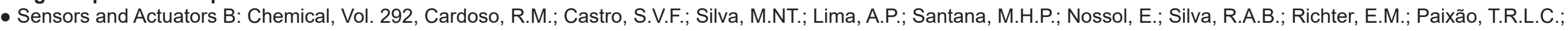
Muñoz, R.A.A.,3D-printed flexible device combining sampling and detection of explosives, Pages No. 308-313, Copyright 2019, with permission from Elsevier. [31]

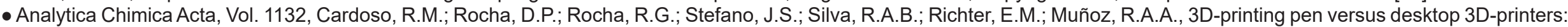

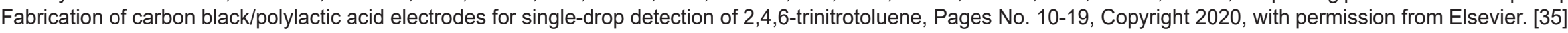

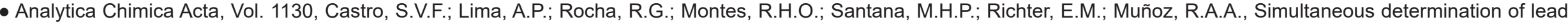
and antimony in gunshot residue using a 3D-printed platform working as sampler and sensor, Pages No. 126-136, Copyright 2020, with permission from Elsevier. [62]

Images reprinted with permission from Wiley:

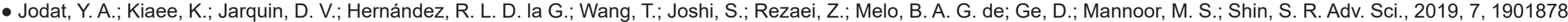

(https://doi.org/10.1002/advs.201901878). Creative Commons Attribution License 2020, with permission from Wiley. [36] 
Palenzuela et al. performed the determination of picric acid using as electrochemical sensor a 3D-printed electrode fabricated by FDM and using a thermoplastic filament composed of graphene and polylactic acid (G/PLA) [21]. The commercialization of conductive filaments has strengthened the development of devices for electrochemical application, including sensing and biosensing [6]. FDM is the most affordable 3D-printing technology and for this reason has become very popular, which has encouraged new users of such 3D-printers. However, generally the FDM 3D-printed carbon-based PLA electrodes requires a surface treatment to improve their electrochemical activity as evidenced by cyclic voltammetric experiments of redox probes before and after treatment [22-29]. The work by Palenzuela et al. proposed a simple treatment with dimethylformamide (DMF) (immersion of the 3D-printed electrode for $10 \mathrm{~min}$ ) [21]. The electrodes were printed in two different designs: disc and ring-shaped electrodes (Table I - Line B).

For these two designs, the calculated electroactive area was about 2.6 and 1.9 times greater than the geometric area of the electrodes in ring and disc-shaped, respectively, which is directly related to the higher roughness of the 3D-printed electrodes. Due the larger active area, the authors chose to use the ring-shaped electrode for the determination of picric acid. For this, the cyclic voltammetry was used to study the electrochemical behavior of the analyte, which was similar to that obtained on a GCE, in addition to allow the determination of the analyte in a wide linear range at low concentrations (5 to $350 \mathrm{mg} \mathrm{L}^{-1}$ ). Moreover, the determination of ascorbic acid was also demonstrated to expand the application of the sensor in different fields [21].

The determination of picric acid was again performed on a 3D-printed G/PLA sensor developed by Novotný et al., as showed in Table I - Line C. The main novelty of this work was a new chemical-free pretreatment of the FDM 3D-printed electrode surface [30]. This treatment consisted of a thermal annealing in a vacuum oven, which promoted a great improvement in the electrochemical activity of the material that was evidenced by cyclic voltammetric scans before and after treatment. Compared to a chemically activated electrode with DMF, the results were also superior, with lower values of capacitance and resistance to charge transfer (Rct). This new type of treatment also provided lower values of $\Delta \mathrm{Ep}$ (difference between oxidation and reduction peaks) and RSD in inter-electrode tests $(n=3)$ when compared with an electrode without any treatment and treated with DMF. The durability of the 3D-printed electrode was evaluated by carrying out analyses after 8 weeks of manufacture and the results showed the conservation of the electrochemical performance. With promising initial studies, the determination of picric acid was successfully performed in a range from 5 to $50 \mathrm{mg} \mathrm{L}^{-1}$, obtaining a LOD of $0.1 \mathrm{mg} \mathrm{L}^{-1}$, results similar to those obtained using the chemically-treated electrode and GCE, which demonstrates that this form of chemical-free treatment emerges as a viable alternative of treatment.

Important for forensic applications, a novel application of 3D-printed G/PLA electrodes was demonstrated as sampler of explosive residues. The sensor was 3D-printed using the FDM technique and treated by a simple mechanical polishing. After this, the device was used for the collection of TNT residues by swiping the sensor over suspected surfaces (working as a swab), and next placed in an electrochemical cell (Table I - Line D), filled with supporting electrode, and the presence of TNT residues was detected by squarewave voltammetry (SWV) [31]. This strategy can be considered as a voltammetric approach of immobilized particles [32], because the voltammetric scan occurs immediately after immobilization of TNT particles that likely continues adhered on the electrode surface during the voltammetric scan. The adherence of the TNT particles is evident because the first scan presents a much higher current response than the following scans for the same 3D-printed electrode used for TNT sampling. Considering experiments is solution,

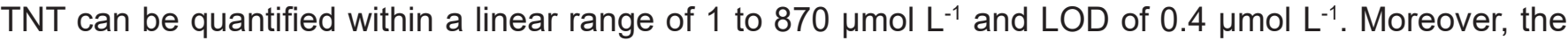
proposed sensor has a satisfactory intra and inter-electrode precisions, with RSD values lower than $10 \%$. For the samples, the amount of TNT collected was estimated using Faraday's Law and the results showed that the 3D-printed sensor acted as a good collector, as it was able to collect 3.2, 20 and 15 ng of TNT on granite, metal and glove surfaces, respectively [31].

Another possibility for obtaining 3D printed sensors was presented by Cardoso and coauthors who performed a comparative study between electrodes obtained by a desktop FDM 3D-printer and a 3D 
printing pen [33]. The 3D-printed electrodes were constructed using a carbon black/polylactic acid (CB/ PLA) filament and were evaluated in two designs: 1) single disc-shaped working electrode placed in an electrochemical with conventional counter and references electrodes and 2) three-electrode system on a planar substrate similar to a commercially-available screen-printed electrode (Table I - Line E). In both cases, the 3D-printed electrodes were electrochemically activated in $0.5 \mathrm{~mol} \mathrm{~L}^{-1} \mathrm{NaOH}$ solution $[27,34]$. The three-electrode planar system presented better inter-electrode reproducibility $(R S D=4 \%)$ and electrochemical performance for the sensing of TNT in a single drop. These results demonstrated the great potential of 3D printing pens in the construction of new devices for the determination of explosives, with a linear range of 5 to $500 \mu \mathrm{mol} \mathrm{L}-1$ and LOD of $1.5 \mu \mathrm{mol} \mathrm{L}-1$, with high precision between measurements [35].

Although the analytical parameters are not superior in comparison to other works reported in the literature, for example the work by Cardoso and collaborators that also proposes the determination of TNT using 3D-printed electrodes [31], this work brings as main advantages the lower cost, the portability of the three-electrode platform and the possibility of analysis in a single drop, which considerably minimizes the consumption of reagents. Moreover, the authors highlight the possibility of reuse of the sensor up to three times through a mechanical polishing step that promotes the renewal of the surface [35].

In addition to the sensors described above, some research groups have used the advantages of 3D printing for the development of more sophisticated electronic devices combined with electrochemical techniques for the determination of explosives. Jodat et al. developed a dual bioink-printed nose constructed with an integrated biosensing system (Table I - Line F) and demonstrated the potential of the device for detection of explosive odor (TNT vapor) [36]. For this, the authors used electrochemical impedance spectroscopy (EIS) associated with a gold-based biosensor functionalized with a TNT-specific peptide. The system was capable to mimic the mechanism of odor detection carried out in the olfactory epithelium and allowed the detection of explosives with high sensitivity, with a wide linear range between 1 and $1000 \mathrm{pg}$ $\mathrm{mL}^{-1}$ and LOD of $0.38 \mathrm{pg} \mathrm{mL}^{-1}$ of TNT. These results are superior to another bioelectronic nose developed by Gao and collaborators for the TNT detection [37]. Due to the characteristics of the device developed by Jodat et al. [36], they also evaluated the degradation of the peptide after the biosensor functionalization process and observed a stability of use for up to 5 days, which indicates a new functionalization step of the substrate every 5 days [36]. Then, this strategy appears as a very interesting alternative for the detection of the explosives in vapor phase using a 3D printed system with high sensitivity, since the vast majority of works, such as those described above, are focused on performing analysis in solution [20,31,35] and residual solid particles [31].

Sempionatto et al. presented a wireless wearable ring-based multiplexed chemical sensor platform that was applied in the determination of DNT in liquid and vapor phase, as showed in Table I - Line G. The device consists of a 3D-printed ring containing electronic microstructures integrated with a screen-printed carbon electrode. For explosive detection, the authors used a semisolid agarose hydrogel to cover the electrode surface and SWV was selected as electrochemical technique for DNT determination [38]. To evaluate the stability and the performance of the proposed sensor, the authors performed experiments in $0.1 \mathrm{~mol} \mathrm{~L}^{-1}$ PBS solution, in which it was possible to observe the occurrence of two clear and well-defined peaks referred to DNT reduction. The linear range was obtained between 0 and $100 \mu \mathrm{g} \mathrm{L}^{-1}$, with clear signals from $10 \mu \mathrm{g} \mathrm{L}^{-1}$ and an LOD estimated to be $4 \mu \mathrm{g} \mathrm{L}^{-1}$. The excellent performance of the system enabled the detection of DNT vapor. The studies were performed with the presence of 5, 50 and $100 \mathrm{mg}$ of DNT in the system constructed by the authors and which contained the ring as a detector, and the SWV scans showed the increase in the current proportional to the mass of DNT. It is important to emphasize that the increase in the incubation time of explosive in the container also results in an increase in the electrochemical signal, which indicates an accumulation effect. Analytical parameters such as reproducibility and selectivity were studied and again the results are promising.

This method appears as an excellent alternative, especially due to the low cost of screen-printed electrodes, which can be easily replaced to ensure the continuous operation of the device. However, the wearable ring has a limitation related to the stability of the agarose gel, which is susceptible to water 
loss and can influence currents acquired by SWV. Stability tests showed that, in a sealed container and in the presence of the analyte, the gel remains stable for a period of $24 \mathrm{~h}$. In addition to this application, the authors also demonstrated the possibility of using the 3D-printed ring for the determination of $\mathrm{H}_{2} \mathrm{O}_{2}$ and organophosphate, demonstrating the great potential of this device for different voltammetric and amperometric analyses [38].

The papers discussed above demonstrate a crescent interest by research groups in applying the advantages of 3D printing technology in the construction of devices with portable characteristics. Taking that into account, the main highlight is the use of the FDM technique that has been widely explored in the development of devices with the most varied designs. Moreover, most of these works showed the need for a surface pre-treatment of the FDM 3D-printed electrode surfaces to improve their electrochemical activity, with a great emphasis on electrochemical treatments and thermal annealing, since they are more ecological alternatives. Along with this, the use the 3D pen offers great promises since they can also be used construct electrochemical devices with similar performance to desktop 3D-printers. Additionally, the use of 3D pens presents as advantages the lower acquisition cost and the use of small amounts of conductive filament to manufacture the sensor [39,40].

Regarding the analytical performance, it is observed that the sensors showed excellent sensitivity, evidenced by the low values of LOD and wide linear ranges at low concentrations. The results are comparable to other sensors already reported in the literature for the determination of picric acid [41,42], DNT [43-45] and TNT [17,46]. However, especially for TNT, it was observed that the analytical characteristics of sensors obtained by 3D printing are still inferior to several studies involving the use of modified electrodes [43,47-49]. At the same time, this type of electrode is commonly associated with previous steps of modification that increase the time and cost of analysis. On the other hand, 3D printed electrodes, in the most of the time, only require simple surface treatments that bring great improvements in their electrochemical performance.

It is important to highlight that the vast majority of the works described here bring low cost as one of the main characteristics of 3D printing, making the sensors disposable. The exception observed is in the work of Cardoso et al. [35], which demonstrated the potential for the reuse of the sensor through surface renewal carried out by mechanical polishing. However, although the sensors are considered disposable, the authors did not present proposals or ways to correctly dispose these devices, which could be an environmental problem. TNT, for example, is considered an environmental pollutant and can cause problems for human health, such as discoloration of hair and skin, aplastic anaemia and liver function disturbances [50]. Therefore, procedures to correctly dispose these sensors aimed at forensic analysis still need to be further explored.

Also related with public security, another area that has attracted great interest in recent years is the examination for the presence or absence of gunshot residue (GSR). These residues are generated during the shot and contain organic and inorganic components, for instance, lead, barium and antimony, which are the main inorganic components [10]. These particles can often adhere in hands and clothes of individuals who fired and can also be found on surfaces closes to the location where the shot was fired [51]. The search for these residues on different surfaces is an important step in the investigation process and can provide information to help elucidate the dynamics of crime events, such as the identification of suspects or the collection of elements forward the identification. As a result of it, highly sensitive and fast methods are necessary, and several researchers have been working to solve these demands.

For the identification of inorganic gunshot residue, the main method used during investigations is scanning electron microscopy with energy dispersive $X$-ray analysis (SEM/EDX). This technique allows the identification of microparticles formed between metals and the collection of this microparticles is performed by devices called as stubs, which favor the adhesion of the residues through abrasive contact with the contaminated surface [52]. Although SEM/EDX is a reliable and reproductive method, a limitation is the lack of portability of the system, which requires the sample to be stored and transported to the laboratory for analysis. In addition, other methods that have also been reported in the literature for this purpose, such 
as using neutron activation analysis (NAA), inductively coupled plasma optical emission spectrometry (ICP OES), inductively coupled plasma mass spectrometry (ICP-MS), and laser-induced breakdown spectroscopy (LIBS), among other techniques [53]; however, they also make use of bulky instrumentation.

In the field of electrochemistry, several sensors have been explored for the identification of GSR, mainly associated with voltammetric stripping methods. The main sensors used for this aim are mercury-based electrodes [54-56] and several types of screen-printed electrodes [57-61].

The use of 3D printing for the development of an electrochemical sensor aimed at the identification of GSR also began to arouse the interest of researchers and was recently reported for the first time by Castro et al. In this work, the authors used a G/PLA electrode obtained by FDM 3D printer to identify the presence of GSR on clothes and hands of shooters; the device and electrochemical cell are summarized in Table I - Line H. The dual device (printed rectangular piece), used as a sampler/sensor, was previously subjected to mechanical polishing, followed by chemical treatment (immersion in DMF for $10 \mathrm{~min}$ ), and later used as a residue collector through direct contact with the studied surfaces. After this, the rectangular piece was coupled to a 3D-printed cell and, through a square-wave anodic stripping voltammetry (SWASV) scan, the detection of nanograms of $\mathrm{Pb}^{2+}$ and $\mathrm{Sb}^{3+}$ was possible, two of the main components present in this type of sample [62]. Prior to the sample analysis steps, the method was optimized in solution and the analytical parameters were evaluated. The authors obtained a wide linear range for the simultaneous determination of $\mathrm{Pb}^{2+}$ and $\mathrm{Sb}^{3+}$ (from 50 to $1500 \mu \mathrm{g} \mathrm{L}^{-1}$ ), and LODs estimated to be 0.5 and $1.8 \mu \mathrm{g} \mathrm{L}^{-1}$, respectively.

The sensor was also evaluated through intra and inter-electrode studies, with proper RSD values obtained for both analytes, indicating the precision of the sensor during measurements and also the reproducibility of 3D printing and previous treatments performed. Due to complexity of GSR samples, the sensor was also evaluated as a function of its selectivity in the presence of other metals and, again, satisfactory results were obtained. Additionally, the authors also demonstrated the possibility of reusing the sensor up to 3 times without considerable loss of performance, performing simple steps of mechanical polishing between each reuse, which is enough to promote cleaning and renewal of the electrode surface. Then, the obtained analytical parameters as well as the results achieved with the samples are comparable and even superior to other works reported in the literature [63,64].

One of the challenges related to electrochemical analysis of GSR is the determination of barium. However, due to the need for application of extreme potentials [65], new strategies such as surface modification with bismuth (incorporation of bismuth in the polymeric matrix) or other material to reduce the hydrogen overvoltage can be investigated. Anyway, this work demonstrates how 3D printing can bring new alternatives for the analysis of GSR in portable systems and opens up opportunities to study new materials and develop new methods to try to solve this limitation and make possible the simultaneous determination of barium, lead and antimony through electrochemical scans.

\section{ILLICIT DRUGS}

Over the recent years, it has been increasing the inquires towards the forensic traces of drugs at crime scenes [66]. Generally, these drugs can be used for recreational purposes due to its sedative, hallucinogenic and/or stimulant effects $[67,68]$. The attractive properties of 3D-printing technology (ease construction of device, low cost and large-scale production, rapid prototyping of complex structures) have allowed its use for the development of portable systems for forensic applications $[6,69,70]$. Moreover, $3 \mathrm{D}$-printing technology could help the scientific police in the control of drugs, as well as, in the development of portable devices to obtain crucial information and chemical evidence on site, avoiding the laborious steps in conventional analysis procedures [31,62]. Currently, colorimetric tests are widely available for qualitative and semi-quantitative preliminary tests of illicit drugs in seized samples $[10,68,71,72]$. These types of tests are known to have desirable characteristics such as rapidity, simplicity, portability and low cost [73-75]. However, the presence of contaminants/adulterants in the sample matrices may induce to false positive or negative results if colorimetric tests are used [76]. The chemical profiling is also carried out in forensic laboratories of many countries using spectroscopic and chromatographic techniques $[77,78]$. 
Nevertheless, they require laborious sample pre-treatment steps, high-cost instrumentation, laboratories with good infrastructure and time-consuming. In this context, electroanalytical methods provide portability, low-cost instrumentation, and adequate limit of detection. The combination of such advantages with largescale and low-cost production of 3D printed electrodes has great potential to increase the popularity of electroanalysis for forensics applications $[6,13,68]$. Table II highlights the main applications devoted to the determination illicit drugs.

Cocaine is one of the most illegal drugs used in the world and can be found with diluents and/or adulterants to increase the bulk and pharmacological effects $[79,80]$. In addition, the determination of adulteration patterns in seized drug samples is important for forensic analysis in which allows to understand the traffic route since the compounds or patterns used to adulterate the cocaine $[71,77]$.

In this sense, Rocha et al. showed for the first time a potential application of 3D-printed electrodes for the identification and quantification of cocaine and adulterants in a forensic scenario [28]. For this purpose, a 3D-printed three-electrode electrochemical cell was used for all electrochemical measurements, which was manufactured using acrylonitrile butadiene styrene (ABS) filament. The 3D-printed working electrode was printed using the commercially-available G/PLA filament. It is worth highlighting that initially the electrochemical response of cocaine was evaluated using non-treated electrodes; however, no cocaine oxidation peak was obtained. Thus, different surface activation procedures of 3D printed electrodes (DMF immersion or electrochemical activation) were explored based on the literature $[26,29,34]$. The best results were achieved by the application of $+1.76 \mathrm{~V}$ (vs. $\left.\mathrm{Ag}|\mathrm{AgCl}| \mathrm{KCl}_{\text {(sat. }}\right)$ for $900 \mathrm{~s}$ followed by application of -1.76 $\mathrm{V}$ (vs. Ag|AgCl|KCl (sat.) $_{\text {) }}$ for $50 \mathrm{~s}$ [29] using $0.1 \mathrm{~mol} \mathrm{~L}^{-1}$ phosphate buffer solution $(\mathrm{pH}=7.4)$ as the supporting electrolyte. Interestingly, the CB/PLA filament was also evaluated to print electrodes for cocaine detection; however, their voltammetric response was not satisfactory even after the same surface treatment applied to G/PLA electrodes, which indicates that graphene or surface functional groups formed after treatment contributed to the improvement electrochemical activity of G/PLA. Using the proposed 3D-printed portable system, the electrochemical sensing of cocaine was described with an acceptable limit of detection (7

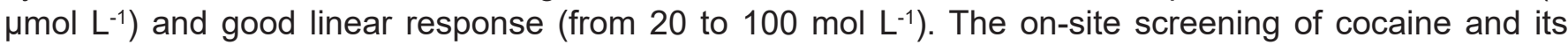
most common contaminants (phenacetin, caffeine, levamisole, lidocaine, paracetamol, procaine and benzocaine) in spiked samples using the proposed system was successfully demonstrated. Hence, the proposed 3D-printed sensor can be used as a quicky test to determine cocaine in the presence of most common adulterants [28].

Rocha and coworkers [81] proposed a new surface treatment of CB/PLA 3D-printed electrodes based on a Photo-Thermal approach with $\mathrm{a} \mathrm{CO}_{2}$ laser to improve their electrochemical performance; such electrodes were applied for the detection of the contaminant paracetamol in a real seized cocaine sample. A scheme of the 3D-printed electrode and cell is showed in Table II - Line J. The authors highlighted that the as-printed electrode provided ill-defined peaks and low conductivity for paracetamol using cyclic voltammetric measurements. However, after the surface post-treatment, a significant enhancement in the electrochemical response of paracetamol was achieved and an increase in peak current of about 3-fold and anticipation of potential peak were acquired. Thus, using the proposed surface treatment of 3D-printed electrodes, the authors estimated an LOD of $0.154 \mu \mathrm{mol} \mathrm{L-1}$. Moreover, a standard addition method was used to determine paracetamol in spiked seized cocaine sample and a recovery value of $97.8 \%$ was obtained.

Similar analytical results were acquired using high-cost commercial carbon-based electrodes [79,8284]. It is important to mention that most of the examples found in the literature for detection of cocaine or adulterants include screen-printed electrodes in which can be used for portable analyses [13]. However, 3D-printing technology enables lower cost of production and customized electrodes, including the manufacture of three electrodes with a reduced cost. 
Table II. 3D printed electrochemical sensors applied for the determination of illicit drugs and contaminants in food and fuel samples

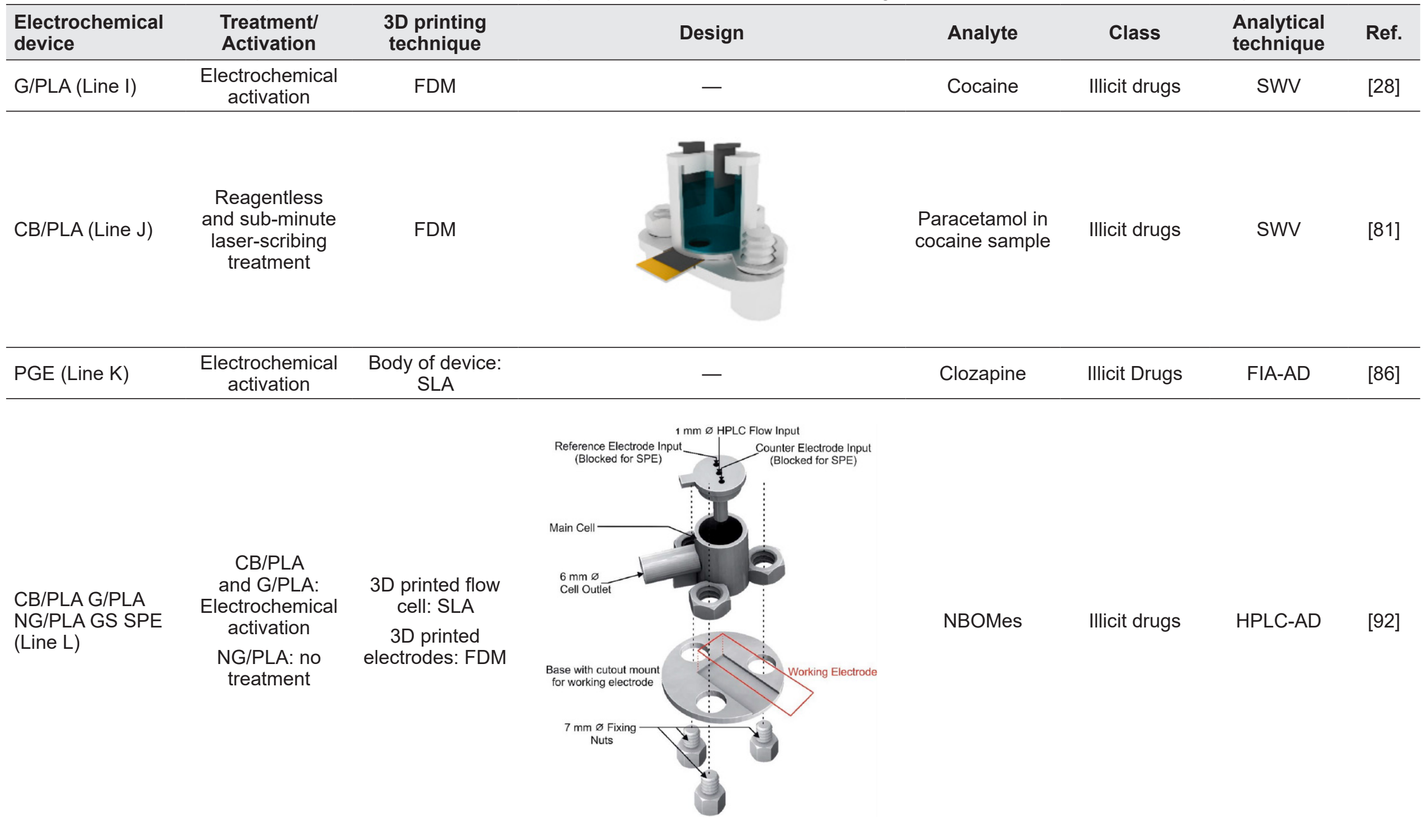


Table II. 3D printed electrochemical sensors applied for the determination of illicit drugs and contaminants in food and fuel samples (Continuation)

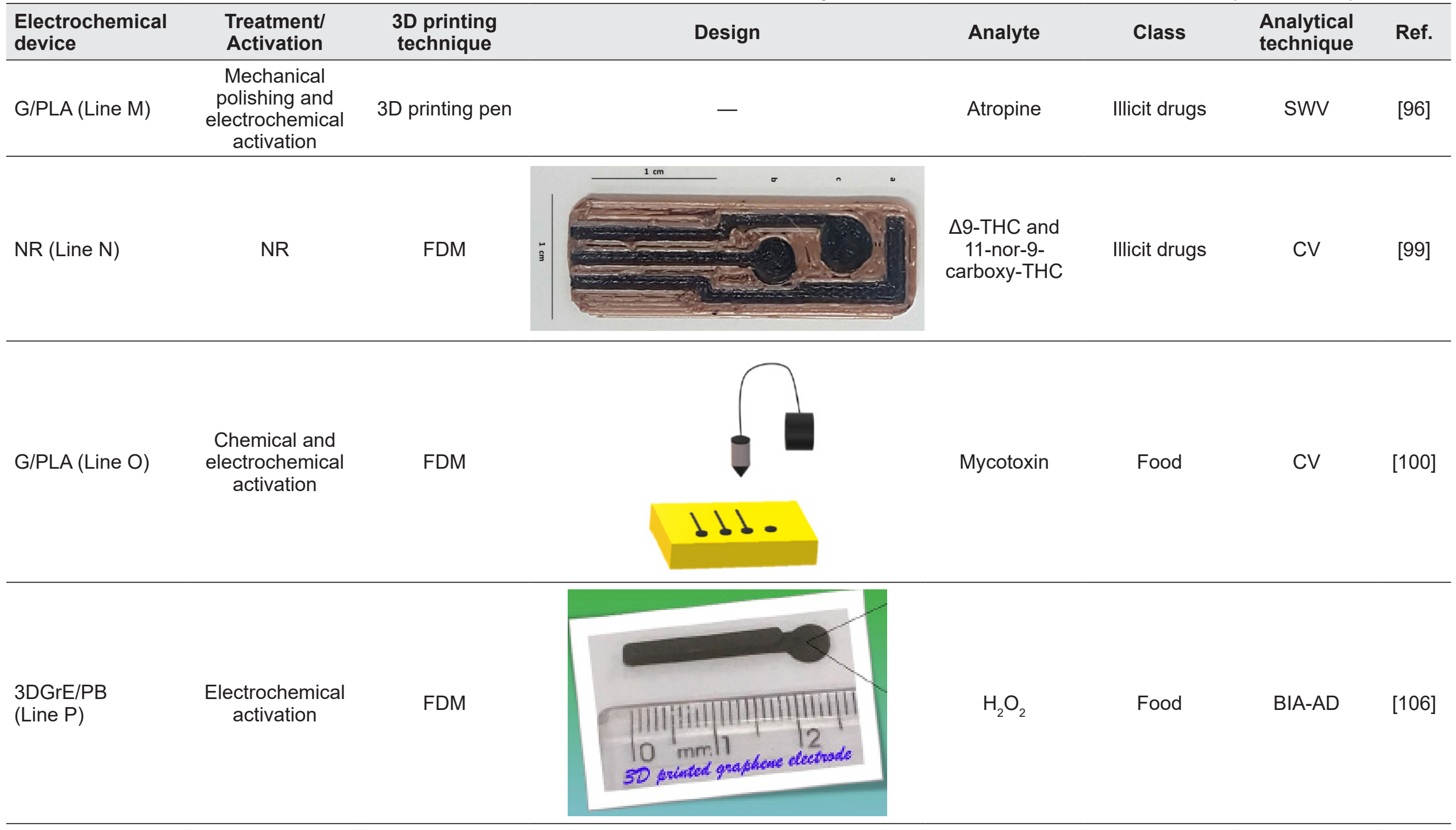


Table II. 3D printed electrochemical sensors applied for the determination of illicit drugs and contaminants in food and fuel samples (Continuation)

\begin{tabular}{|c|c|c|c|c|c|c|c|}
\hline $\begin{array}{l}\text { Electrochemical } \\
\text { device }\end{array}$ & $\begin{array}{l}\text { Treatment/ } \\
\text { Activation }\end{array}$ & $\begin{array}{l}\text { 3D printing } \\
\text { technique }\end{array}$ & Design & Analyte & Class & $\begin{array}{l}\text { Analytical } \\
\text { technique }\end{array}$ & Ref. \\
\hline PB/G/PLA (Line Q) & $\begin{array}{l}\text { Chemical } \\
\text { activation }\end{array}$ & FDM & & $\mathrm{H}_{2} \mathrm{O}_{2}$ & Food & BIA-AD & [109] \\
\hline CB/PLA (Line R) & $\begin{array}{l}\text { Mechanical } \\
\text { polishing and } \\
\text { electrochemical } \\
\text { activation }\end{array}$ & FDM & & $\mathrm{Cu}^{2+}$ & Fuel & SWASV & [118] \\
\hline
\end{tabular}


Table II. 3D printed electrochemical sensors applied for the determination of illicit drugs and contaminants in food and fuel samples (Continuation)

\begin{tabular}{llllll}
\hline $\begin{array}{l}\text { Electrochemical } \\
\text { device }\end{array}$ & $\begin{array}{l}\text { Treatment/ } \\
\text { Activation }\end{array}$ & $\begin{array}{c}\text { 3D printing } \\
\text { technique }\end{array}$ & Design & Analyte & Class \\
\hline
\end{tabular}

CB/PLA (Line S) $\begin{gathered}\text { Electrochemical } \\ \text { activation }\end{gathered} \quad 3 D$ printing pen

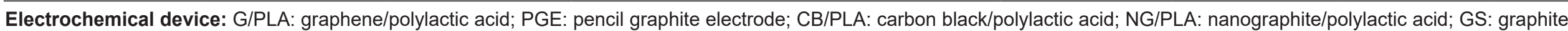
sheet; SPE: screen-printed graphite microelectrode; NR: not reported; 3DGrE/PB and PB/G/PLA: 3D printed graphene electrode with Prussian blue;

3D printing technique: SLA: stereolithography; FDM: fused deposition modelling

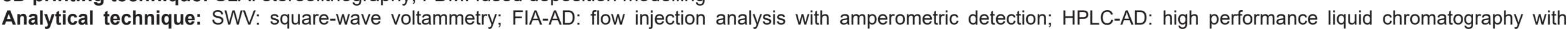
amperometric detection; CV: cyclic voltammetry; BIA-AD: batch injection analysis with amperometric detection; SWASV: square-wave anodic-stripping-voltammetry.

Images reprinted from Elsevier:

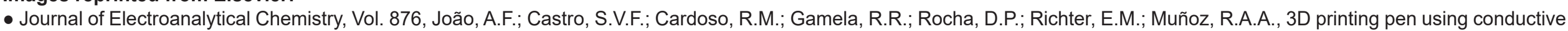
filaments to fabricate affordable electrochemical sensors for trace metal monitoring, Pages No. 114701, Copyright 2020, with permission from Elsevier. [39]

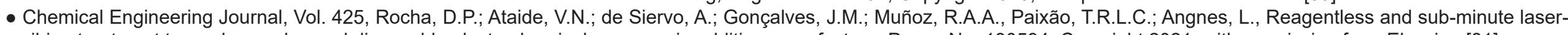

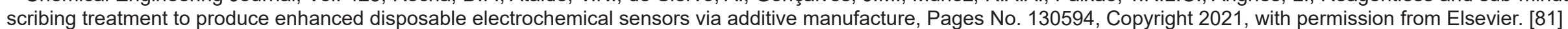

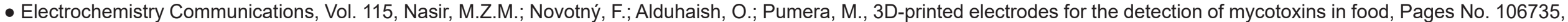
Creative Commons 2020, with permission from Elsevier. [100]

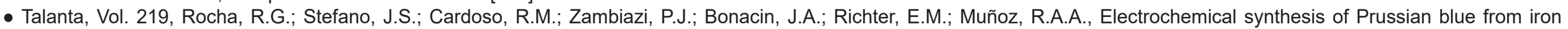

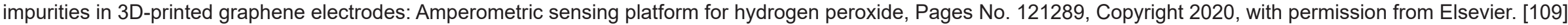

Images reprinted from The Royal Society of Chemistry:

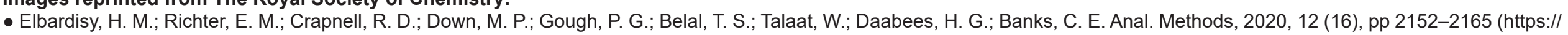
doi.org/10.1039/d0ay00500b) - Published by The Royal Society of Chemistry. [92]

Images reprinted from Brazilian Journal of Forensic Sciences:

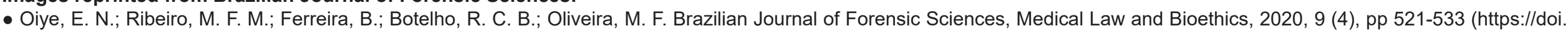
org/10.17063/bjfs9(4)y2020521-533) - Published by Brazilian Journal of Forensic Sciences, Medical Law and Bioethics. [99]

Images reprinted with permission from American Chemical Society:

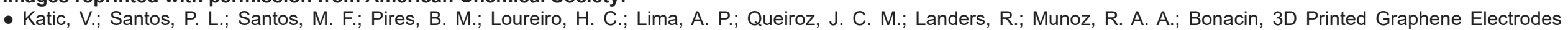

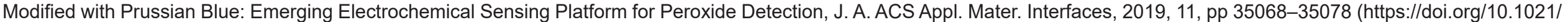
acsami.9b09305). Copyright (C) 2019 American Chemical Society. [106]

Images reprinted with permission from Springer:

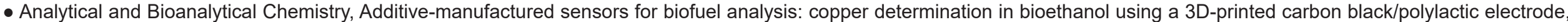
João, A.F.; Squissato, A.L.; Richter, E.M.; Muñoz, R.A.A., Copyright @ 2020. [118] 
Clozapine is a therapeutic, antipsychotic drug approved for the treatment of schizophrenia and, due to its sedative effect, has been used as date rape drug or drug of abuse. This type of drug is commonly given to victims for non-medical reasons (abuse intentions). For this reason, the situation generates a demand for selective and sensitive methods to detect clozapine and its metabolites in biological samples collected from the victims [85]. In this context, Senel and Alachkar developed a 3D-printed sensing microfluidic device with amperometric detection using graphite pencil as working electrode (Table II - Line K) [86]. The 3D model of the electrochemical cell is entirely fabricated by 3D printing using a stereolithography (SLA) 3D printer. The authors highlighted the use of SLA for microchannel printing due to its ability to produce high-accurate and isotropic parts in a range of advanced materials with smooth surface finish. Moreover, the resolution of SLA printing is higher than FDM-based 3D printing technique for the formation of microstructures. As working and reference electrodes, $0.5 \mathrm{~mm}$ pencil graphite rod and $0.5 \mathrm{~mm}$ silver wire were inserted into commercially available threaded fittings along the 3D printed microfluidic channel. Nevertheless, the electrodes were not directly adapted in the 3D printed device, that was adapted in a threaded fitting and connected to the device. Before use, the pencil graphite electrode (formed by the pencil graphite rod) was electrochemically activated by 50 cyclic voltammograms in the range $0.0 \mathrm{~V}$ to $+1.2 \mathrm{~V}$ (vs. PGE) with a scan rate of $100 \mathrm{mV} \mathrm{s}^{-1}$ in $0.1 \mathrm{~mol} \mathrm{~L}^{-1}$ phosphate buffer $(\mathrm{pH}=7.4)$ [87]. The device was successfully applied to detect clozapine in serum samples with a limit of detection of $24 \mathrm{nmol} \mathrm{L}^{-1}$ and good recovery values (96-108\%).

Novel psychoactive substances (NPS) are a class of compounds that have been designed to mimic recreational drugs and are commonly produced in clandestine laboratories [88,89]. An important class of NPS are phenethylamine derivatives, such as, 25F-NBOMe, 25C-NBOMe, and 25F-NBOMe. This class are potent agonist of the 5-HT2A receptor and can produce psychoactive effects [90,91]. Recently, Elbardisy et al. reported that a complete electrochemical system (wall jet flow cell and working electrodes) can be produced by 3D-printed technology in order to coupling high performance liquid chromatography and amperometric detection [92]. The 3D-printed flow cell was designed to allow the use of different working electrodes such as screen-printed sensors, graphite sheets, and FDM 3D-printed electrodes (fabricated with Proto-Pasta ${ }^{\circledR}$, Black-Magic ${ }^{\circledR}$ and homemade conductive filaments [93]). The 3D printed flow cell was produced using an SLA 3D printer and photopolymer resin. The working electrodes (printed rectangular pieces) were produced using a FDM 3D printer and were positioned at the bottom of the flow cell and the geometric area was delimited with a rubber O-ring (single unprinted part) (Table II - Line L).

Before use, the 3D-printed working electrodes were activated using procedures described in the literature [29,34]. The 3D-printed carbon black electrode (produced with Proto-Pasta ${ }^{\circledR}$ filament) was electrochemically activated using $0.5 \mathrm{~mol} \mathrm{~L}^{-1} \mathrm{NaOH}$ as supporting electrolyte $(+1.4 \mathrm{~V} / 200 \mathrm{~s}$ followed by $-1.0 \mathrm{~V} / 200 \mathrm{~s}$ ) [34]. On the other hand, the 3D printed G/PLA (produced from Black Magic ${ }^{\circledR}$ filament) was electrochemical activated using the procedure described by Santos et al. (+1.8 V/900 s and cyclic voltammetric scans from $0.0 \mathrm{~V}$ to $-1.8 \mathrm{~V}$ in $0.1 \mathrm{~mol} \mathrm{~L}^{-1}$ phosphate buffer; $\mathrm{pH} 7.4$ ) [29]. As a proof-of-concept, the performance of the three 3D-printed electrodes was tested through the amperometric detection of four NBOMes (NBOMe derivates, 25F-NBOMe, 25C-NBOMe and 25F-NBOMe) after their chromatographic separation. The following ranges of limits of detection $(10.2-15.3,4.4-11.0,3.2-5.0$, and $14.4-16.1 \mu \mathrm{g}$ $\left.\mathrm{mL}^{-1}\right)$ and recoveries values in simulated drug samples (98 - 103, $96-100,99-101$, and $\left.97-103 \%\right)$ were obtained with SPEs, activated 3D-printed CB/PLA, graphite sheets and 3D printed homemade filament as working electrodes, respectively.

According to the authors, the AM/3D printed flow cell had several advantages over the commercial systems: (i) simple geometrical configuration, (ii) short production time, (iii) low cost, (iv) higher sensitivity of the wall-jet design, (v) efficient mass transport of the analyte onto the electrode surface, (vi) simple assembly, (vii) versatility toward working electrode substrates and, (viii) high flow rate tolerance $(2.5 \mathrm{~mL}$ $\left.\min ^{-1}\right)$. 
Atropine is a natural tropane alkaloid from the Datura stramonium (jimsonweed) and Atropa belladonna (deadly nightshade) and usually employed for medicinal purposes. Moreover, atropine can be used in criminal activities by poisoning beverages. The most popular case using atropine as a deadly poison was the case of Dr. Paul Agutter who tried to murder his wife by spiking her beverage with atropine. Chromatographic methods are generally employed for determining atropine [94,95], however, this type of analytical method involves high cost and sample preparation in which are not attractive for forensic applications where a rapid and portable sensing approach is required. Electrochemical procedures can be used to overcome these limitations, because they enable versatile, low-cost and portable analytical methods. Therefore, João and coworkers [96] developed a method for detection of atropine in beverage samples (white wine, vodka, whisky and energy drink) using 3D-printed G/PLA electrodes (Table II - Line M). 3D pen was employed to construction of working electrode using customized acrylic substrates to guide the reproducible application of the G/PLA filament by the pen. Before use, the 3D-printed electrode was electrochemically activated in basic medium to expose the conductive sites, improving the analytical response of atropine.

Thus, using square-wave voltammetric determination, a linear concentration range between 5 and 60 $\mu \mathrm{mol} \mathrm{L} \mathrm{L}^{-1}$, with a limit of detection of $1 \mu \mathrm{mol} \mathrm{L} \mathrm{L}^{-1}$ and good recoveries values (104-120\%) were achieved. Considering that the victim drinks around $250 \mathrm{~mL}$ of beverage, the atropine average fatal dose is $1.38 \mathrm{mmol}$ $\mathrm{L}^{-1}$, thus the proposed method is appropriate to determine atropine in this type of the sample.

Cannabis, also known as Marijuana, is the most commonly addictive drug used worldwide. It stimulates cells in the brain to release dopamine, creating euphoria and memory loss. The chemical responsible for most of marijuana's psychological effects is the tetrahydrocannabinol (THC) [97]. In the human body, THC is metabolized in 11-nor-9-carboxy-THC (also known as 11-COOH-THC), being found in biological fluids such as plasmas and oral fluid between 3 and 6 hours after consumption [98].

In this sense, Oiye et al. [99] proposed a method for the detection of THC in aqueous solution and its metabolite (11-COOH-THC) in saliva using 3D printing technology for construction of device. The electrode design was similar to screen-printed electrodes commercially-available on the market, as summarized in Table II - Line N. After printing, the reference electrode was covered with a silver ink to create a silver pseudo reference electrode. The authors showed a detection of $15 \mu \mathrm{mol} \mathrm{L}^{1} \mathrm{THC}$ in aqueous solutions and $170 \mu \mathrm{mol} \mathrm{L}^{1} 11-\mathrm{COOH}-\mathrm{THC}$ in real saliva samples. Moreover, the analysis using different electrodes presented a variation of $8 \%$ in the current peak response that indicates good reproducibility of the proposed method. It is important to mention that Oiye and coworkers did not present important analytical parameters, such as limit of detection and quantification, linear range and recovery values for the analysis of spiked samples; however, the proposed method is a promising work to expand the results in forensic area.

In regard to the analytical performance of these sensors, all works presented herein show appropriate limit of detection values for forensic applications. Moreover, electrochemical procedures associated to 3D printed technology are versatile alternatives by reason of being low cost, good reproducibility, portable and acceptable limit of detection. However, the electrochemical response of the as printed electrodes is relatively poor if compared to other carbonaceous surfaces (glassy carbon, carbon paste, etc.). Thus, all works found in the literature highlighted the need of pre-treatments (activations) to reduce of insulating polymer, exposing of the conductive material.

\section{FOOD AND FUELS}

The 3D-printing technology, specially FDM, has also enabled the production of electrochemical sensors for food and fuel analysis and depicted in Table II. Food analysis is an important topic for discussion among international institutions, particularly, in view of the potential from terrorism, also known, bioterrorism [100]. This term is defined as deliberate release of biological agents (fungi, bacteria, viruses, and other microorganisms) to cause death or damage to health in humans, animals or plants. These agents are typically found in nature or synthetized and mutated by humans. This practice started during World War I, when the bacterium Bacillus anthracis was used to cause infection anthrax [10]. In this context, one class of compounds which has received great attention are the mycotoxins. Mycotoxins are naturally metabolites 
produced by certain fungi in which can be found in foodstuffs, including cereals, nuts, spices, dried fruits, apple and coffee beans. This class of compounds can cause a variety of adverse human health effects such as immune deficiency and cancer [101].

In this sense, Nasir and coauthors proposed a 3D-printed electrode for the detection of the Zearalenone, a type of Mycotoxins, produced by the Fusarium fungi species, using commercially-available conductive filaments composed by G/PLA (Table II - Line O) [100]. For this purpose, the authors submitted the 3D-printed electrode an immersion in DMF for 10 minutes. After washing and drying, electrochemical activation was achieved at a potential of $2.5 \mathrm{~V}$ (vs. $\mathrm{Ag} \mid \mathrm{AgCl}_{\mathrm{KCCl}}$ (sat) $)$ in phosphate buffer solution ( $\left.\mathrm{pH} 7.2\right)$ [102]. The activated 3D-printed G/PLA electrodes displayed a good linear response in the concentration range of 10 to $300 \mu \mathrm{mol} \mathrm{L-1}$ with a limit of detection of $0.340 \mu \mathrm{mol} \mathrm{L}^{-1}$. The authors did not present results in real samples, but the results were promising for the electrochemical detection of mycotoxins in food samples.

The modification of 3D-printed electrode surfaces using chemical modifiers has been investigated for the development of electrochemical sensors for the detection of analytes in food samples with improved detectability, sensitivity and selectivity. Prussian blue (PB) is a relatively cheap and stable electrocatalyst used as an electrode modifier, due to its good spectroscopic and electrochemical characteristics [103,104]. Briefly, PB is a structure containing alternate Fe (II) and Fe (III) atoms connected by cyanide that can be easily oxidized or reduced according to the applied potentials. PB is also known as an artificial enzyme peroxidase due to its properties of electrocatalytic reduction of hydrogen peroxidase at potentials close to $0.0 \mathrm{~V}$ [103]. The electrochemical properties of this material make its use an attractive strategy for $\mathrm{H}_{2} \mathrm{O}_{2}$ sensing to control food adulteration, such as milk samples [105]. $\mathrm{H}_{2} \mathrm{O}_{2}$ has been commonly used a preservative in milk as well as disinfectant agent in milk processing equipment; however, this molecule is considered an adulterant and its content in milk requires routine monitoring.

Katic et al. reported the use of PB for the modification of 3D-printed G/PLA electrodes for selective detection of $\mathrm{H}_{2} \mathrm{O}_{2}$ in milk and mouthwash samples (Table II - Line P). The PB synthesis was achieved by applying a potential of $+0.4 \mathrm{~V}$ (vs. Ag|AgCl|KCl$\left.{ }_{\text {(sat.) }}\right)$ for $600 \mathrm{~s}$ in a solution containing $1 \mathrm{mmol} \mathrm{L}^{-1}\left[\mathrm{Fe}(\mathrm{CN})_{6}\right]^{3-}$ and $1 \mathrm{mmol} \mathrm{L}^{-1} \mathrm{FeCl}_{3}$, using $0.1 \mathrm{~mol} \mathrm{~L}^{-1} \mathrm{KCl}$ acidified with $0.01 \mathrm{~mol} \mathrm{~L}^{-1} \mathrm{HCl}$ as the supporting electrolyte [106]. The performance of the 3D-printed G/PLA electrode modified with PB was compared with results obtained with other working electrodes (glassy-carbon, platinum and gold). According to the authors, the PB film showed higher stability of the 3D-printed electrode surface in acid medium. Thus, the authors showed the applicability of the modified 3D printed electrode for detection of $\mathrm{H}_{2} \mathrm{O}_{2}$ in milk samples. For that, the 3D-printing modified electrode was coupled to a 3D-printed batch injection analysis (BIA) cell [107]. The proposed method presented a wide linear range $\left(1.0\right.$ to $\left.700 \mu \mathrm{mol} \mathrm{L} \mathrm{L}^{-1}\right)$ and a limit of detection of 0.37 $\mu \mathrm{mol} \mathrm{L}{ }^{-1}$ for the selective detection of $\mathrm{H}_{2} \mathrm{O}_{2}$ at $0.0 \mathrm{~V}$ (vs. Ag|AgCl|KCl$($ sat.) $)$. Moreover, milk and mouthwash samples were analyzed and good recoveries values (97 to 120\%) were obtained, which indicates absence of sample matrix effects. Finally, an interference study was performed considering potential interfering species commonly found in biological fluids (dopamine, ascorbic acid, and uric acid). In this study, the selective detection of hydrogen peroxide using the modified 3D-printing electrode was confirmed.

Commercially conductive filaments for FDM 3D-printers have enabled the rapid development of new sensors, mainly the filament based on PLA and graphene. However, Browne and collaborators reported the presence of metallic impurities in this type of commercial filament (G/PLA from BlackMagic $($ ). In addition, as already reported in the literature, the presence of metallic impurities can affect the electrochemical characteristics of the 3D-printed material, such as for water splitting [108]. PB films can be designed electrochemically in the presence of iron (III) cations and ferricyanide, as described above [104]. In this sense, Rocha and coworkers proposed the electrochemical synthesis of iron hexacyanoferrate, using the $\mathrm{Fe}$ (III) provided as impurities in the commercially-available filament used in the experiment (Table II - Line Q) [109]. The presence of iron impurities was confirmed by X-ray spectroscopic analysis. For the PB formation, two hundred voltammetric cycles were performed in presence of $1 \mathrm{mmol} \mathrm{L}^{-1}$ potassium ferricyanide, using $0.1 \mathrm{~mol} \mathrm{~L}^{-1} \mathrm{KCl}$ acidified with $0.01 \mathrm{~mol} \mathrm{~L}^{-1} \mathrm{HCl}$ over -0.3 to $+1.2 \mathrm{~V}$ (vs. $\left.\mathrm{Ag} \mid \mathrm{AgCl} \mathrm{KCl}_{\text {(sat. })}\right)$ 
and scan rate of $50 \mathrm{mV} \mathrm{s}^{-1}$. Before the surface modification, the 3D-printed electrode was submitted to DMF immersion for 30 min to remove insulating material [23].

After this procedure, a typical profile of PB-modified electrodes was observed by cyclic voltammetry. This modified 3D-printed electrode was then evaluated for amperometric detection of $\mathrm{H}_{2} \mathrm{O}_{2}$ and a linear response between 1 and $700 \mu \mathrm{mol} \mathrm{L}^{-1}$ and the limit of detection of $0.56 \mu \mathrm{mol} \mathrm{L}^{-1}$ were obtained. Moreover, the authors showed the detection of $\mathrm{H}_{2} \mathrm{O}_{2}$ in milk samples with good recoveries (between 94 and 101\%).

The use of alternative fuels has increased dramatically over the last several years, as more people look for ways to save money, reduce environmentally harmful emissions, and decrease their dependence on fossil fuels [110]. Biofuels were introduced to reduce engine emissions and provide better environmental concerns and socioeconomic issues, in addition to being renewable energies over mineral fuel $[111,112]$. Fossil fuels are still being created today by underground heat and pressure, so they are being consumed more rapidly than they are being created. For that reason, fossil fuels are considered non-renewable; that is, they are not replaced as soon as we use them. Renewable energy is a promising alternative solution because it is clean and environmentally safe [113].

Modern society's quality of life undoubtedly depends on liquid fuels for the development of agricultural, commercial, and industrial activities [10]. Biofuel quality control involves the determination of metal and metalloid content. These species play an important role because they may modify the efficiency of biofuel production as well as the stability of these products. Furthermore, some metals are toxic and generate environmental pollution [114]. Due to the growing use and manufacture of biodiesel, both commercially and inhouse, the exposure to combustion of these fuels is increasing. Metals are adsorbed or attached on the structures of organic compounds or hydrocarbons emitted from combustion of vehicle engines and can be of different toxicological proprieties. The chemical composition of particle emission is related to the quality of the burned fuel and vehicular exhaust condition and may affect its toxicity. Many people who make biodiesel at home are working with several gallons of fuel at a time [110] and the attendants of gas stations are daily exposed to the inhalation of smoke from the engine combustion that carries particles of heavy metal and gradually degrades their health. Many death cases are reported regularly which are investigated forensically to determine the cause and manner of death so as to establish them as the cases of homicidal, suicidal or accidental metal poisoning and to know whether poisoning resulted from acute, chronic or acute-on-chronic exposure [115]. Studies suggest that exposure to nanoparticles causes serious damage to health, such as lung inflammation, asthma, chronic obstruction of arteries and lungs, cell death, obstruction and accumulation in the olfactory bulb, access to brain damage, tumor necrosis, oxidative stress, neural effects, heart problems, and even death [116].

Additionally, the content of metals in engine oils and fuels can be helpful in forensic cases involving automobile accidents [117]. The concentration profile of metals in used oil or fuels found at the accident scene can aid in the identification of the cars involved in the accident. Hence, the determination of metals in such samples (oils and fuels) can be an important evidence in the forensic scenario.

Recently, the upgrading and replacement of products have become rapidly increasing. On other hand, the 3D printing or additive manufacturing is emerging as a technology that could revolutionize how studies are conducted in numerous scientific research fields [102]. On the research front, additive manufacturing technology is creating new paradigms in different research fields, such as bioprinting, electronic printing, as well as environmental-related fields. Currently, 3D-printed conductive filaments containing carbonaceous materials have been presented as promising electrochemical sensors for control and monitoring bioethanol fuel quality $[39,118]$.

3D-printed CB/PLA electrodes have been successfully applied for copper detection in fuel bioethanol samples [118]. The electrochemical cell and working electrodes were 3D-printed in a similar way that was previously reported in the first section. Copper is one of the metals controlled by regulatory agencies of fuels due to its catalytic action on the degradation of fuels. The main regulatory framework for ethanol biofuel quality monitoring are the American Society for Testing and Materials (ASTM D4814), the Brazilian National Agency for Natural Gas and Biofuels [119,120] and the European Standardization (EN 15376). These agencies establish the specificities and basic rules of fuel quality monitoring. In their protocols, 
some contaminants, antioxidants, metal deactivators, and dispersants used to improve the stability of middle distillate fuels limits and physicochemical properties of biofuels are indicated. Considering the contamination with copper, techniques involving high instrumentation costs and bulky equipment, such as ICP OES, ICP-MS, and atomic absorption spectroscopy (AAS), are proposed as official methods. In this context, 3D-printing technologies provide a tool for prototyping simple or complex structures for electrochemical sensing, due to its ability to produce highly versatile, tailored-shaped devices in a low-cost and fast way with minimized waste. Table II - Line R shows the use of an electrode printed with CB-PLA filament was proposed for the determination of copper in bioethanol [118]. The analytical features of the proposed voltammetric method include a wide linear response concentration range of 10 to $300 \mu \mathrm{L} \mathrm{L}^{-1}$ $(R=0.999)$, high inter-day precision $8 \%\left(n=10\right.$, for $\left.20 \mu \mathrm{g} \mathrm{L}^{-1}\right)$ and a LOD of $0.097 \mu \mathrm{g} \mathrm{L}^{-1}$ using $180 \mathrm{~s}$ as deposition time. Bioethanol samples were simply diluted in the supporting electrolyte $\left(0.1 \mathrm{~mol} \mathrm{~L}^{-1} \mathrm{HCl}\right)$ before analysis (30:70 v/v ethanol:water proportion). The upper limit concentration of copper in bioethanol samples is $56 \mu \mathrm{g} \mathrm{L}^{-1}$ (according to the Brazilian and European agencies that present a stricter limit for this metal). Therefore, the method can be used for quality control of bioethanol samples.

Sensors used in previous works were prepared following laborious and time-consuming steps, such as synthesis of composites [121-123] or modification of sensor surface [124,125]. Furthermore, the use of mercury film modified electrodes, despite their excellent properties in electrochemical determination of metals, have fallen into disuse due to the toxicity of the metal to analysts and environment [126]. Therefore, the use of 3D-printing technology may provide advantages in the manufacture of electrochemical sensors with better detection properties than commercial gold disk [127] or screen-printed gold electrodes [128].

The combination of a 3D pen with 3D printers to fabricate low-cost electrochemical sensors was also explored to determine metals in bioethanol [39]. 3D-printed templates produced using a FDM printer and ABS filament were manually filled with conductive CB/PLA material using a 3D pen to fabricate sensors as previously reported (Table II - Line S) $[33,35]$. Bioethanol samples were similarly diluted in $0.1 \mathrm{~mol} \mathrm{~L}^{-1} \mathrm{HCl}$ used as the supporting electrolyte for the simultaneous determination of copper and lead. The presence of lead as well copper in bioethanol can be associated with corrosion of metallic components. Although the content of lead is not controlled by regulatory agencies, the presence of lead in bioethanol results in higher emission of this toxic metal to the atmosphere. The analytical features of the development method using SWASV for the determination of both metals provided wide linear ranges, up to $200 \mu \mathrm{g} \mathrm{L}^{-1}$ for $\mathrm{Pb}(\mathrm{II})$ and up to $400 \mu \mathrm{g} \mathrm{L}^{-1}$ for $\mathrm{Cu}(\mathrm{II})$ and, LOD values of 1 and $2 \mu \mathrm{g} \mathrm{L}{ }^{-1}$ for $\mathrm{Pb}(\mathrm{II})$ and $\mathrm{Cu}$ (II) using a deposition time of $100 \mathrm{~s}$. The inter-electrode precision (for $n=3$ ) was $2.8 \%$ which indicates that the electrode construction procedure is highly precise as well as the SWASV determination. The presence of other metallic interfering species, such as $\mathrm{Fe}(\mathrm{III}), \mathrm{Cd}(\mathrm{II}), \mathrm{Zn}(\mathrm{II})$ and $\mathrm{Hg}(\mathrm{II})$, was evaluated and no interference was verified in the detection of $\mathrm{Pb}(\mathrm{II})$ and $\mathrm{Cu}(\mathrm{II})$. Recovery values (ranged from $83 \%$ to 107\%) for the analysis of fortified samples also attested for the absence of sample matrix. Some additional interesting observation of this work is the increase in the analytical response of both metals by the presence of mercury, which is likely to occur considering previous works using mercury-film electrodes and increase in the sensitivity of lead detection when copper is also present in solution (the literature also has shown benefits of copper films in the detection of lead).

The sensor obtained by combination of a 3D pen with 3D printers has better or equivalent performance in terms of detection limit when compared with previously published works. The limit of detection is closely dependent on the deposition time applied to the measurements. Nascimento et al. [129] and Tormin et al. [124] using shorter preconcentration times (30 s and $90 \mathrm{~s}$, respectively) obtained lower LOD values for both metals; however, they used sensors which are not environmentally friendly and cannot be used as disposable electrodes. Several works employed commercial electrodes which have a relatively high cost compared to a 3D-printed electrode, and electrodes prepared following laborious and time-consuming steps, such as synthesis of composites $[122,130]$ or modification of electrode surface $[121,124,125]$. 


\section{CONCLUDING REMARKS AND PERSPECTIVES}

This review shows that forensic chemistry can be largely benefited by the 3D printing technology. FDM 3D printers have enabled the fabrication of electrochemical sensors for a wide range of analytes of forensic interests. Carbon-based filaments have explored and quickly adapted for the printing of electrodes and devices applied for the detection of explosives, metallic GSR, illicit drugs, and contaminants in food and fuels. The knowledge on electrochemistry of carbon-based electrodes have been extended to understand the electrochemical processes occurred at the 3D-printed thermoplastic electrodes. New contributions have been reported, including the need for surface treatment for improved electrochemical activity. Other 3D-printing techniques, such SLM, have been explored to produce sensors, although they may be not so advantageous considering the high cost. However, many other 3D-printing techniques can still be explored for unlimited applications. Lab-on-a-chip devices taking the advantage of printing microfluidic channels with printed electrodes embedded along the channels by means of single-step fabrication protocols are highly promising for on-site analysis of complex forensic samples.

The preliminary works highlighted in this review using 3D-printed carbon-based electrodes have shown the excellent performance for sensing nitroaromatic explosives. Potentially, the simultaneous determination of two or more types of explosives is a challenge to be overcome. The same is true for the simultaneous determination of illicit drugs or at least the selective detection of single illicit drug in suspected sample. Most forensic samples require the selective identification of an illicit substance that can be attained by using chemical modifiers incorporated at the 3D-printed surface or within the polymeric matrix. The challenge still remains on the proper incorporation of the chemical modifier in a way that stable, reproducible, selective and sensitive electrode are obtained. PB-modified 3D-printed electrodes are a successful proof-of-concept case herein presented.

Due to the immeasurable possibilities that 3D printing offers, new applications can be envisaged going beyond the applications herein presented. Creative designs coupled with innovative surface modification protocols can be one feasible direction to be followed towards the development of high-performance electrochemical sensors and devices for forensic applications.

\section{Conflicts of interest}

The authors declare no conflict of interest.

\section{Acknowledgements}

The authors are grateful to the agencies CAPES (001), CNPq (427731/2018-6, 307271/2017-0, and 208504/2018-6), INCTBio (CNPq grant no. 465389/2014-7), CNPq/TWAS (137634/2017-0), and FAPEMIG (RED-00042-16 and APQ-03141-18) for the financial support.

\section{REFERENCES}

1. Huang, S. H.; Liu, P.; Mokasdar, A.; Hou, L. Int. J. Adv. Manuf. Technol., 2013, 67, pp 1191-1203 (https://doi.org/10.1007/s00170-012-4558-5).

2. Silver, A. Nature, 2019, 565, pp 123-124 (https://doi.org/10.1038/d41586-018-07853-5).

3. Kitson, P. J.; Glatzel, S.; Chen, W.; Lin, C. G.; Song, Y. F.; Cronin, L. Nat. Protoc., 2016, 11, pp 920-936 (https://doi.org/10.1038/nprot.2016.041).

4. Zhang, M.; Mei, H.; Chang, P.; Cheng, L. J. Mater. Chem. A, 2020, 8, pp 10670-10694 (https://doi. org/10.1039/d0ta02099k).

5. Browne, M. P.; Redondo, E.; Pumera, M. Chem. Rev., 2020, 120 (5), pp 2783-2810 (https://doi. org/10.1021/acs.chemrev.9b00783).

6. Cardoso, R. M.; Kalinke, C.; Rocha, R. G.; Santos, P. L.; Rocha, D. P.; Oliveira, P. R.; Janegitz, B. C.; Bonacin, J. A.; Richter, E. M.; Munoz, R. A. A. Anal. Chim. Acta, 2020, 1118, pp 73-91 (https:// doi.org/10.1016/j.aca.2020.03.028).

7. Carrasco-Correa, E. J.; Simó-Alfonso, E. F.; Herrero-Martínez, J. M.; Miró, M. TrAC - Trends Anal. Chem., 2021, 136, 116177 (https://doi.org/10.1016/j.trac.2020.116177). 
8. Waheed, S.; Cabot, J. M.; Macdonald, N. P.; Lewis, T.; Guijt, R. M.; Paull, B.; Breadmore, M. C. Lab Chip, 2016, 16 (11), pp 1993-2013 (https://doi.org/10.1039/c6lc00284f).

9. Carew, R. M.; Errickson, D. J. Forensic Sci., 2020, 65 (5), pp 1752-1760 (https://doi.org/10.1111/15564029.14442).

10. Oliveira, L. P.; Rocha, D. P.; Araujo, W. R.; Muñoz, R. A. A.; Paixão, T. R. L. C.; Salles, M. O. Anal. Methods, 2018, 10, pp 5135-5163 (https://doi.org/10.1039/c8ay01389f).

11. To, K. C.; Ben-Jaber, S.; Parkin, I. P. ACS Nano, 2020, 14 (9), pp 10804-10833 (https://doi. org/10.1021/acsnano.0c01579).

12. Hay, C. E.; Lee, J.; Silvester, D. S. J. Electroanal. Chem., 2020, 872, 114046 (https://doi.org/10.1016/j. jelechem.2020.114046).

13. Araujo, W. R.; Cardoso, T. M. G.; Rocha, R. G.; Santana, M. H. P.; Munoz, R. A. A.; Richter, E. M.; Paixão, T. R. L. C.; Coltro, W. K. T. Anal. Chim. Acta, 2018, 1034, pp 1-21. (https://doi.org/10.1016/j. aca.2018.06.014).

14. Yu, H. A.; DeTata, D. A.; Lewis, S. W.; Silvester, D. S. TrAC - Trends Anal. Chem., 2017, 97, pp 374-384 (https://doi.org/10.1016/j.trac.2017.10.007).

15. Holubowitch, N. E.; Crabtree, C.; Budimir, Z. Anal. Chem., 2020, 92, pp 11617-11626 (https://doi. org/10.1021/acs.analchem.0c01174).

16. Castro, S. V. F.; Cardoso, R. M.; Santana, M. H. P.; Richter, E. M.; Munoz, R. A. A. Talanta, 2019, 203, pp 106-111 (https://doi.org/10.1016/j.talanta.2019.05.048).

17. Wang, Z.; Liu, H.; Li, C.; Chen, X.; Weerasooriya, R.; Wei, J.; Lv, J.; Lv, P.; Wu, Y. Talanta, 2020, 208, 120410 (https://doi.org/10.1016/j.talanta.2019.120410).

18. Dettlaff, A.; Jakóbczyk, P.; Ficek, M.; Wilk, B.; Szala, M.; Wojtas, J.; Ossowski, T.; Bogdanowicz, R. J. Hazard. Mater., 2020, 387, 121672 (https://doi.org/10.1016/j.jhazmat.2019.121672).

19. Stefano, J. S.; Lima, A. P.; Nascentes, C. C.; Krzyzaniak, S. R.; Mello, P. A.; Gonçalves, J. M.; Richter, E. M.; Nossol, E.; Munoz, R. A. A. J. Solid State Electrochem., 2020, 24, pp 121-129 (https:// doi.org/10.1007/s10008-019-04465-5).

20. Tan, C.; Nasir, M. Z. M.; Ambrosi, A.; Pumera, M. Anal. Chem., 2017, 89 (17), pp 8995-9001 (https:// doi.org/10.1021/acs.analchem.7b01614).

21. Palenzuela, C. L. M.; Novotný, F.; Krupička, P.; Sofer, Z.; Pumera, M. Anal. Chem., 2018, 90, pp 5753-5757 (https://doi.org/10.1021/acs.analchem.8b00083).

22. Silva, V. A. O. P.; Fernandes-Junior, W. S.; Rocha, D. P.; Stefano, J. S.; Muñoz, R. A. A.; Bonacin, J. A.; Janegitz, B. C. Biosensors and Bioeletronics, 2020, 170, 112684 (https://doi.org/10.1016/j. bios.2020.112684).

23. Kalinke, C.; Neumsteir, N. V.; Aparecido, G. D. O.; Ferraz, T. V. D. B.; dos Santos, P. L.; Janegitz, B. C.; Bonacin, J. A. Analyst, 2020, 145 (4), pp 1207-1218 (https://doi.org/10.1039/C9AN01926J).

24. Wirth, D. M.; Sheaff, M. J.; Waldman, J. V.; Symcox, M. P.; Whitehead, H. D.; Sharp, J. D.; Doerfler, J. R.; Lamar, A. A.; LeBlanc, G. Anal. Chem., 2019, 91 (9), pp 5553-5557 (https://doi.org/10.1021/ acs.analchem.9b01331).

25. Redondo, E.; Muñoz, J.; Pumera, M. Carbon, 2021, 175, pp 413 - 419 (https://doi.org/10.1016/j. carbon.2021.01.107).

26. Gusmão, R.; Browne, M. P.; Sofer, Z.; Pumera, M. Electrochem. Commun., 2019, 102, pp 83-89 (https://doi.org/10.1016/j.elecom.2019.04.004).

27. Rocha, D. P.; Squissato, A. L.; Silva, S. M.; Richter, E. M.; Muñoz, R. A. A. Electrochim. Acta, 2020, 335, 135688 (https://doi.org/10.1016/j.electacta.2020.135688).

28. Rocha, R. G.; Ribeiro, J. S.; Santana, M. H.; Richter, E. M.; Munoz, R. A. A. Anal. Methods, 2021, 13, pp 1788-1794 (https://doi.org/10.1039/D1AY00181G).

29. Santos, P. L.; Katic, V.; Loureiro, H. C.; dos Santos, M. F.; dos Santos, D. P.; Formiga, A. L. B.; Bonacin, J. A. Sensors Actuators B Chem., 2019, 281 (2), pp 837-848 (https://doi.org/10.1016/j. snb.2018.11.013). 
30. Novotny, F.; Urbanova, V.; Plutnar, J.; Pumera, M. Appl. Mater. Interfaces, 2019, 11, pp 35371-35375 (https://doi.org/10.1021/acsami.9b06683).

31. Cardoso, R. M.; Castro, S. V. F.; Silva, M. N. T.; Lima, A. P.; Santana, M. H. P.; Nossol, E.; Silva, R. A. B.; Richter, E. M.; Paixão, T. R. L. C.; Muñoz, R. A. A. Sensors Actuators B. Chem., 2019, 292, pp 308-313 (https://doi.org/10.1016/j.snb.2019.04.126).

32. Silveira, G. D.; Di Turo, F.; Dias, D.; Silva, J. A. F. J. Solid. State Electrochem., 2020, 24, pp 26332652 (https://doi.org/10.1007/s10008-020-04720-0).

33. Cardoso, R. M.; Castro, S. V. F.; Stefano, J. S.; Muñoz, R. A. A. J. Braz. Chem. Soc., 2020, 31 (9), pp 1764-1770 (https://dx.doi.org/10.21577/0103-5053.20200129).

34. Richter, E. M.; Rocha, D. P.; Cardoso, R. M.; Keefe, E. M.; Foster, C. W.; Munoz, R. A. A.; Banks, C. E. Anal. Chem., 2019, 91, pp 12844-12851 (https://doi.org/10.1021/acs.analchem.9b02573).

35. Cardoso, R. M.; Rocha, D. P.; Rocha, R. G.; Stefano, J. S.; Silva, R. A. B.; Richter, E. M.; Munoz, R. A. A. Anal. Chim. Acta, 2020, 1132, pp 10-19 (https://doi.org/10.1016/j.aca.2020.07.034).

36. Jodat, Y. A.; Kiaee, K.; Jarquin, D. V.; Hernández, R. L. D. G.; Wang, T.; Joshi, S.; Rezaei, Z.; Melo, B. A. G.; Ge, D.; Mannoor, M. S.; Shin, S. R. Adv. Sci., 2019, 7, 1901878 (https://doi.org/10.1002/ advs.201901878).

37. Gao, K.; Li, S.; Zhuang, L.; Qin, Z.; Zhang, B.; Huang, L.; Wang, P. Biosensors and Bioelectronics, 2018, 102, pp 150-156 (https://doi.org/10.1016/j.bios.2017.08.055).

38. Sempionatto, J. R.; Mishra, R. K.; Martín, A.; Tang, G.; Nakagawa, T.; Lu, X.; Campbell, A. S.; Lyu, K. M.; Wang, J. ACS Sensors, 2017, 2 (10), pp 1531-1538 (https://doi.org/10.1021/acssensors.7b00603).

39. João, A. F.; Castro, S. V. F.; Cardoso, R. M.; Gamela, R. R.; Rocha, D. P.; Richter, E. M.; Muñoz, R. A. A. J. Electroanal. Chem., 2020, 876, 114701 (https://doi.org/10.1016/j.jelechem.2020.114701).

40. Oliveira, F. M.; Melo, E. I.; Silva, R. A. B. Sensors Actuators, B Chem., 2020, 321, 128528 (https:// doi.org/10.1016/j.snb.2020.128528).

41. James, S.; Chishti, B.; Ansari, S. A.; Alothman, O. Y.; Fouad, H.; Ansari, Z. A.; Ansari, S. G. Journal of Electronic Materials, 2018, 47, pp 7505-7513 (https://doi.org/10.1007/s11664-018-6692-9).

42. Mahyari, M. Int. J. Environ. Anal. Chem., 2016, 96, pp 1455-1468 (https://doi.org/10.1080/0306731 9.2016.1268606).

43. Zeng, W.; Manoj, D.; Sun, H.; Yi, R.; Huang, X.; Sun, Y. J. Electroanal. Chem., 2019, 833, pp 527535 (https://doi.org/10.1016/j.jelechem.2018.12.028).

44. Rani, S.; Sharma, B.; Kapoor, S.; Malhotra, R.; Varma, R. S.; Dilbaghi, N. Appl. Sci., 2019, 9 (22), 4952 (https://doi.org/10.3390/app9224952).

45. Ahmad, K.; Mohammad, A.; Mathur, P.; Mobin, S. M. Electrochim. Acta, 2016, 215, pp 435-446 (https://doi.org/10.1016/j.electacta.2016.08.123).

46. Dettlaff, A.; Jakóbczyk, P.; Ficek, M.; Wilk, B.; Szala, M.; Wojtas, J.; Ossowski, T.; Bogdanowicz, R. Journal of Hazardous Materials, 2020, 387, 121672 (https://doi.org/10.1016/j.jhazmat.2019.121672).

47. Lima, A. P.; Almeida, P. L. M. R.; Sousa, R. M. F.; Richter, E. M.; Nossol, E.; Munoz, R. A. A. Journal of Electroanalytical Chemistry, 2019, 851, 113385 (https://doi.org/10.1016/j.jelechem.2019.113385).

48. Niu, F.; Shao, Z.; Tao, L.; Ding, Y. Journal of Colloid and Interface Scince, 2021, 594, pp 848-856 (https://doi.org/10.1016/j.jcis.2021.03.091).

49. Leibl, N.; Duma, L.; Gonzato, C.; Haupt, K. Bioelectrochemistry, 2020, 135, 107541 (https://doi. org/10.1016/j.bioelechem.2020.107541).

50. Yew, Y. T.; Ambrosi, A.; Pumera, M. Scientific Reports, 2016, 16, 33276 (https://doi.org/10.1038/ srep33276).

51. Goudsmits, E.; Sharples, G. P.; Birkett, J. W. Trends Anal. Chem., 2015, 74, pp $46-57$ (https://doi. org/10.1016/j.trac.2015.05.010).

52. Charles, S.; Geusens, N.; Vergalito, E.; Nys, B. Forensic Sci. Int., 2020, 2, pp 416-418 (https://doi. org/10.1016/j.fsisyn.2020.01.011).

53. Feeney, W.; Pyl, C. V.; Bell, S.; Trejos, T. Forensic Chem., 2020, 19, pp 100250 (https://doi. org/10.1016/j.forc.2020.100250). 
54. Woolever, C. A.; Starkey, D. E.; Dewald, H. D. Forensic Sci. Int., 1999, 102, pp $45-50$ (https://doi. org/10.1016/S0379-0738(99)00036-5).

55. Woolever, C. A.; Dewald, H. D. Forensic Sci. Int., 2001, 117, pp 185-190 (https://doi.org/10.1016/ S0379-0738(00)00402-3).

56. Erden, S.; Durmus, Z.; Kiliç, E. Electroanalysis, 2011, 23 (8), pp 1967-1974 (https://doi.org/10.1002/ elan.201000612).

57. Bandodkar, A. J.; O’Mahony, A. M.; Ramírez, J.; Samek, I. A.; Anderson, S. M.; Windmiller, J. R.; Wang, J. Analyst, 2013, 138 (18), pp 5288-5295 (https://doi.org/10.1039/c3an01179h).

58. Mahony, A. M. O.; Windmiller, J. R.; Samek, I. A.; Bandodkar, A. J.; Wang, J. Electrochem. Commun., 2012, 23, pp 52-55 (https://doi.org/10.1016/j.elecom.2012.07.004).

59. Mahony, A. M. O.; Samek, I. A.; Sattayasamitsathit, S.; Wang, J. Anal. Bioanal. Chem., 2014, 86, pp 8031-8036 (https://doi.org/10.1021/ac5016112).

60. Hashim, N. H. M.; Zain, Z. M.; Jaafar, M. Z. MATEC Web Conferences, 2016, 59, 04005 (https://doi. org/10.1051/matecconf/20165904005).

61. Trejos, T.; Pyl, C. V; Menking-Hoggatt, K.; Alvarado, A. L.; Arroyo, L. E. Forensic Chem., 2018, 8, pp 146-156 (https://doi.org/10.1016/j.forc.2018.02.006).

62. Castro, S. V. F.; Lima, A. P.; Rocha, R. G.; Cardoso, R. M.; Santana, H. P.; Richter, E. M.; Munoz, R. A. A.; Montes, R. H. O. Anal. Chim. Acta, 2020, 1130, pp 126-136 (https://doi.org/10.1016/j. aca.2020.07.033).

63. Trejos, T.; Pyl, C. V.; Menking-Hoggatt, K.; Alvarado, A. L.; Arroyo, L. E. Forensic Chemistry, 2018, 8, pp 146-156 (https://doi.org/10.1016/j.forc.2018.02.006).

64. Ott, C. E.; Dalzell, K. A.; Calderón-Arce, P. J.; Alvarado-Gámez, A. L.; Trejos, T. Arroyo, L. E. J. Forensic Sci., 2020, 65 (6), pp 1935-1944 (https://doi.org/10.1111/1556-4029.14548).

65. Vuki, M.; Shiu, K.; Galik, M.; Mahony, A. M. O.; Wang, J. Analyst, 2012, 137, pp 3265-3270 (https:// doi.org/10.1039/c2an35379b).

66. United Nations Office on Drugs and Crime. Crime Scene and Physical Evidence Awareness for NonForensic Personnel. New York, 2009, pp 1-36.

67. Shbair, M. K. S.; Lhermitte, M. Ann. Pharm. Fr., 2010, 69 (3), pp 136-147 (https://doi.org/10.1016/j. pharma.2010.03.005).

68. Jones, N. S.; Comparin, J. H. Forensic Sci. Int. Synerg., 2020, 2, pp 608-669 (https://doi.org/10.1016/j. fsisyn.2020.01.019).

69. Foster, C. W.; Down, M. P.; Zhang, Y.; Ji, X.; Rowley-Neale, S. J.; Smith, G. C.; Kelly, P. J.; Banks, C. E. Sci. Rep., 2017, 7 (1), 42233 (https://doi.org/10.1038/srep42233).

70. Tully, J. J.; Meloni, G. N. Anal. Chem., 2020, 92 (22), pp 14853-14860 (https://doi.org/10.1021/acs. analchem.0c03299).

71. Silva, G. O.; de Araujo, W. R.; Paixão, T. R. L. C. Talanta, 2018, 176, pp 674-678 (https://doi. org/10.1016/j.talanta.2017.08.082).

72. Erickson, J. S.; Shriver-Lake, L. C.; Zabetakis, D.; Stenger, D. A.; Trammell, S. A. Sensors, 2017, 17 (8), 1769 (https://doi.org/10.3390/s17081769).

73. Scott Jr, L. J. Microgram, 1973, 6, pp 179-181.

74. Marcelo, M. C. A.; Mariotti, K. C.; Ortiz, R. S.; Ferrão, M. F.; Anzanello, M. J. Microchem. J. , 2016, 127, pp 87-93 (https://doi.org/10.1016/j.microc.2016.02.012).

75. Osterloh, J. Clin. Pharmacokinet., 1993, 24 (5), pp 355-361 (https://doi.org/10.2165/00003088199324050-00001).

76. Tsumura, Y.; Mitome, T.; Kimoto, S. Forensic Sci. Int., 2005, 155 (2-3), pp 158-164 (https://doi. org/10.1016/j.forsciint.2004.11.011).

77. Botelho, É. D.; Cunha, R. B.; Campos, A. F. C.; Maldaner, A. O. J. Braz. Chem. Soc., 2014, 25 (4), pp 611-618 (https://doi.org/10.5935/0103-5053.20140008). 
78. Maldaner, A. O.; Botelho, É. D.; Zacca, J. J.; Melo, R. C. A.; Costa, J. L.; Zancanaro, I.; Oliveira, C. S. L.; Kasakoff, L. B.; Paixão, T. R. L. C. J. Braz. Chem. Soc., 2016, 27 (4), pp 719-726 (https://doi. org/10.5935/0103-5053.20150321).

79. Freitas, J. M.; Ramos, D. L. O.; Sousa, R. M. F.; Paixão, T. R. L. C.; Santana, M. H. P.; Muñoz, R. A. A.; Richter, E. M. Sensors Actuators B Chem., 2017, 243, pp 557-565 (https://doi.org/10.1016/j. snb.2016.12.024).

80. Brunt, T. M.; Rigter, S.; Hoek, J.; Vogels, N.; van Dijk, P.; Niesink, R. J. M. Addiction, 2009, 104 (5), pp 798-805 (https://doi.org/10.1111/j.1360-0443.2009.02532.x).

81. Rocha, D. P.; Ataide, V. N.; de Siervo, A.; Gonçalves, J. M.; Munoz, R. A. A.; Paixão, T. R. L. C.; Angnes, L. Chem. Eng. Sci, 2021, 425, 130594 (https://doi.org/10.1016/j.cej.2021.130594).

82. Rocha, D. P.; Dornellas, R. M.; Nossol, E.; Richter, E. M.; Silva, S. G.; Santana, M. H. P.; Munoz, R. A. A. Electroanalysis, 2017, 29, pp 2418-2422. (https://doi.org/10.1002/elan.201700437).

83. De Jong, M.; Florea, A.; Vries, A.; van Nuijs, A. L. N.; Covaci, A.; Durme, F. V.; Martins, J. C.; Samyn, N.; De Wael, K. Anal. Chem., 90 (8), pp 5290-5297 (https://doi.org/10.1021/acs.analchem.8b00204).

84. Oiye, E. N.; Figueiredo, N. B.; Andrade, J. F.; Tristão, H. M.; Oliveira, M. F. Forensic Sci. Int., 2009, 192, pp 94-97 (https://doi.org/10.1016/j.forsciint.2009.08.004).

85. Kang, M.; Kim, E.; Winkler, T. E.; Banis, G.; Liu, Y.; Kitchen, C. A.; Kelly, D. L.; Ghodssi, R.; Payne, G. F. Biosens. Bioelectron., 2017, 95, pp 55-59 (https://doi.org/10.1016/j.bios.2017.04.008).

86. Senel, M.; Alachkar, A. Lab Chip, 2021, 21 (2), pp 405-411 (https://doi.org/10.1039/D0LC00970A).

87. Purushothama, H. T.; Nayaka, Y. A.; Vinay, M. M.; Manjunatha, P.; Yathisha, R. O.; Basavarajappa, K. V. J. Sci. Adv. Mater. Devices, 2018, 3 (2), pp 161-166 (https://doi.org/10.1016/j.jsamd.2018.03.007).

88. Miliano, C.; Serpelloni, G.; Rimondo, C.; Mereu, M.; Marti, M.; De Luca, M. A. Front. Neurosci., 2016, 10, pp 1-21 (https://doi.org/10.3389/fnins.2016.00153).

89. Hondebrink, L.; Lonkhuyzen, J. J. N.; Van Der Gouwe, D.; Brunt, T. M. Drug Alcohol Depend., 2015, 147, pp 109-115 (https://doi.org/10.1016/j.drugalcdep.2014.11.033).

90. De Andrade, A. F. B.; Gonzalez-Rodriguez, J. Analyst, 2019, 144 (9), pp 2965-2972 (https://doi. org/10.1039/c9an00062c).

91. Odoardi, S.; Romolo, F. S.; Strano-Rossi, S. Forensic Sci. Int., 2016, 265, pp 116-120 (https://doi. org/10.1016/j.forsciint.2016.01.037).

92. Elbardisy, H. M.; Richter, E. M.; Crapnell, R. D.; Down, M. P.; Gough, P. G.; Belal, T. S.; Talaat, W.; Daabees, H. G.; Banks, C. E. Anal. Methods, 2020, 12 (16), pp 2152-2165 (https://doi.org/10.1039/ d0ay00500b).

93. Foster, C. W.; Elbardisy, H. M.; Down, M. P.; Keefe, E. M.; Smith, G. C.; Banks, C. E. Chem. Eng. J., 2020, 381, 122343 (https://doi.org/10.1016/j.cej.2019.122343).

94. Zhang, P.; Li, Y.; Liu, G.; Sun, X.; Zhou, Y.; Deng, X.; Liao, Q.; Xie, Z. J. Sep. Sci., 2014, 37 (19), pp 2664-2674 (https://doi.org/10.1002/jssc.201400534).

95. Boros, B.; Farkas, A.; Jakabová, S.; Bacskay, I.; Kilár, F.; Felinger, A. Chromatographia, 2010, 71, pp 43-49 (https://doi.org/10.1365/s10337-010-1524-y).

96. João, A. F.; Rocha, R. G.; Matias, T. A.; Richter, E. M.; Petruci, J. F. S.; Munoz, R. A. A. Microchem. J., 2021, 167, 106324 (https://doi.org/10.1016/j.microc.2021.106324).

97. Kenney, J. E. Drug Test. Anal., 2010, 3 (3), pp 163-165 (https://doi.org/10.1002/dta.151).

98. Huestis, M. A. Cheminform, 2007, 38 (47), pp 1770-1804 (https://doi.org/10.1002/chin.200747256).

99. Oiye, E. N.; Ribeiro, M. F. M.; Ferreira, B.; Botelho, R. C. B.; Oliveira, M. F. Brazilian Journal of Forensic Sciences, Medical Law and Bioethics, 2020, 9 (4), pp 521-533 (https://doi.org/10.17063/ bjfs9(4)y2020521-533).

100. Nasir, Z. M. M.; Novotný, F.; Alduhaish, O.; Pumera, M. Electrochem. Commun., 2020, 115, 106735 (https://doi.org/10.1016/j.elecom.2020.106735).

101. Maragos, C. World Mycotoxin J., 2010, 3 (4), pp 369-383 (https://doi.org/10.3920/WMJ2010.1240). 
102. Browne, M. P.; Novotný, F.; Sofer, Z.; Pumera, M. ACS Appl. Mater. Interfaces, 2018, 10 (46), pp 40294-40301 (https://doi.org/10.1021/acsami.8b14701).

103. Karyakin, A. A.; Karyakina, E. E. Sensors Actuators B Chem., 1999, 57 (1-3), pp 268-273 (https:// doi.org/10.1016/S0925-4005(99)00154-9).

104. Nossol, E.; Zarbin, A. J. G. Adv. Funct. Mater., 2009, 19 (24), pp 3980-3986 (https://doi.org/10.1002/ adfm.200901478).

105. Heli, H.; Sattarahmady, N.; Zare, S. N. RSC Adv., 2015, 5 (27), pp 21005-21011 (https://doi. org/10.1039/c5ra01405k).

106. Katic, V.; Santos, P. L.; Santos, M. F.; Pires, B. M.; Loureiro, H. C.; Lima, A. P.; Queiroz, J. C. M.; Landers, R.; Munoz, R. A. A.; Bonacin, J. A. ACS Appl. Mater. Interfaces, 2019, 11, pp 35068-35078 (https://doi.org/10.1021/acsami.9b09305).

107. Cardoso, R. M.; Mendonça, D. M. H.; Silva, W. P.; Silva, M. N. T.; Nossol, E.; da Silva, R. A. B.; Richter, E. M.; Muñoz, R. A. A. Anal. Chim. Acta, 2018, 1033, pp 49-57 (https://doi.org/10.1016/j. aca.2018.06.021).

108. Browne, M. P.; Pumera, M. Chem. Commun., 2019, 55, pp 8374-8377 (https://doi.org/10.1039/ c9cc03774h).

109. Rocha, R. G.; Stefano, J. S.; Cardoso, R. M.; Zambiazi, P. J.; Bonacin, J. A.; Richter, E. M.; Munoz, R. A. A. Talanta, 2020, 219, 121289 (https://doi.org/10.1016/j.talanta.2020.121289).

110. Goodman, M. R.; Kaley, E. A.; Finney, E. E. Forensic Sci. Int., 2016, 263, pp 10-26 (https://doi. org/10.1016/j.forsciint.2016.03.040).

111. Ogunkunle, O.; Ahmed, N. A. Energy Reports, 2019, 5, pp 1560-1579 (https://doi.org/10.1016/j. egyr.2019.10.028).

112. Nogueira, T.; Cordeiro, D. S.; Muñoz, R. A. A.; Fornaro, A.; Miguel, A. H.; Andrade, M. F. Bioethanol and Biodiesel as Vehicular Fuels in Brazil: Assessment of Atmospheric Impacts from the Long Period of Biofuels Use. In: Krzysztof Biernat (Ed.). Biofuels - Status and Perspective, $1^{\text {th }}$ edition. InTech, 2015, vol. 18, pp 377-412 (https://doi.org/10.5772/60944).

113. Demirbas, A. Biodiesel: A Realistic Fuel Alternative for Diesel Engines. Springer, 2008, pp 1-108.

114. Sánchez, R.; Sánchez, C.; Lienemann, C.; Todolí, J. J. Anal. At. Spectrom., 2015, 30, pp 64-101 (https://doi.org/10.1039/C4JA00202D).

115. Verma, A. International Journal for Research in Applied Science \& Engineering Technology, 2018, 6 (1), pp 1089-1092 (https://doi.org/10.22214/ijraset.2018.1165).

116. Guarieiro, L. L. N.; Guarieiro, A. L. N. Biofuels - Status and Perspective: Chapter 11, 2015 (http:// dx.doi.org/10.5772/60110).

117. Kim, Y.; Kim, N. Y.; Park, S. Y.; Lee, D.; Lee, J. H. Forensic Sci. Int., 2013, 230, pp 58-67 (https://doi. org/10.1016/j.forsciint.2013.01.013).

118. João, A. F.; Squissato, A. L.; Richter, E. M.; Muñoz, R. A. A. Anal. Bioanal. Chem., 2020, 412, pp 2755-2762 (https://doi.org/10.1007/s00216-020-02513-y).

119. Agência Nacional do Petróleo, Gás Natural e Biocombustíveis. Resolução $n^{\circ} 807$, de 23 de janeiro de 2020. Brasil, ANP, 2020. Available at: https://www.in.gov.br/web/dou/-/resolucao-n-807-de-23-dejaneiro-de-2020-239635261 [Accessed July 2021].

120. Agência Nacional do Petróleo, Gás Natural e Biocombustíveis. Resolução $n^{\circ} 30$, de 23 de junho de 2016. Brasil, ANP, 2016. Available at: https://www.in.gov.br/web/guest/materia/-/asset_ publisher/Kujrw0TZC2Mb/content/id/23064622/do1-2016-06-24-resolucao-n-30-de-23-de-junhode-2016-23064478 [Accessed July 2021].

121. Takeuchi, R. M.; Santos, A. L.; Padilha, P. M.; Stradiotto, N. R. Talanta, 2007, 71 (2), pp 771-777 (https://doi.org/10.1016/j.talanta.2006.05.035).

122. Cesarino, I.; Marino, G.; Cavalheiro, E. T. G. Fuel, 2010, 89 (8), pp 1883-1888 (https://doi. org/10.1016/j.fuel.2009.11.037). 
123. Neto, S. Y.; Viégas, H. D. C.; Almeida, J. M. S.; Cavalheiro, E. T. G.; Araújo, A. S.; Marques, E. P.; Marques, A. L. B.; Electroanalysis, 2015, 28 (5), pp 1035-1043 (https://doi.org/10.1002/ elan.201500619).

124. Tormin, T. F.; Narciso, L. C. D.; Richter, E. M.; Munoz, R. A. A. Fuel, 2014, 117, pp 952-956 (https:// doi.org/10.1016/j.fuel.2013.10.038).

125. Oliveira, M. F.; Saczk, A. A.; Okumura, L. L.; Fernandes, A. P.; Moraes, M.; Stradiotto, N. R. Anal. Bioanal. Chem., 2004, 380, pp 135-140 (https://doi.org/10.1007/s00216-004-2733-8).

126. Ariño, C.; Serrano, N.; Díaz-Cruz, J. M. Esteban, M. Anal. Chim. Acta, 2017, 990, pp 11-53 (https:// doi.org/10.1016/j.aca.2017.07.069).

127. Munoz, R. A. A.; Angnes, L. Microchem. J., 2004, 77 (2), pp 157-162 (https://doi.org/10.1016/j. microc.2004.02.010).

128. Almeida, E. S.; Richter, E. M.; Munoz, R. A. A. Anal. Chim. Acta, 2014, 837, pp 38-43 (https://doi. org/10.1016/j.aca.2014.05.031).

129. Nascimento, D. S.; Insausti, M.; Band, B. S. F.; Lemos, S. G. Fuel, 2014, 137, pp 172-178 (https:// doi.org/10.1016/j.fuel.2014.07.100).

130. Saciloto, T. R.; Cervini, P.; Cavalheiro, É. T. G. Electroanalysis, 2014, 26 (12), pp 2664-2676 (https:// doi.org/10.1002/elan.201400282). 